\title{
Age-related decline of the unfolded protein response in the heart promotes protein misfolding and cardiac pathology
}

Christoph Hofmann ${ }^{1,2,3}$, Erik A. Blackwood ${ }^{3,4}$, Tobias Jakobi ${ }^{1,2,4}$, Clara Sandmann ${ }^{1,2}$, Julia Groß ${ }^{1,2}$, Nicole Herzog ${ }^{1,2}$, Randal J. Kaufman ${ }^{5}$, Hugo A. Katus ${ }^{1,2}$, Mirko Völkers ${ }^{1,2}$, Christopher C. Glembotski $^{3,4}$, Shirin Doroudgar ${ }^{1,2,4 *}$

${ }^{1}$ Department of Internal Medicine III (Cardiology, Angiology, and Pneumology), Heidelberg University Hospital, 69120 Heidelberg, Germany.

${ }^{2}$ DZHK (German Center for Cardiovascular Research), Partner Site Heidelberg/Mannheim, 69120 Heidelberg, Germany.

${ }^{3}$ SDSU Heart Institute and Department of Biology, San Diego State University, San Diego, CA 92182, USA.

${ }^{4}$ Department of Internal Medicine and the Translational Cardiovascular Research Center, University of Arizona College of Medicine - Phoenix, Phoenix, USA.

${ }^{5}$ Degenerative Diseases Program, Sanford Burnham Prebys Medical Discovery Institute, La Jolla, CA, USA.

*Address correspondence to Shirin Doroudgar, Department of Internal Medicine, University of Arizona College of Medicine - Phoenix, 475 N. 5th Street, Phoenix, AZ 85004, USA. Tel: 602-8273237; E-mail: sdoroudgar@arizona.edu

Running Head: Age-related decline of the UPR in the heart

Keywords: Unfolded protein response; UPR; proteostasis; protein misfolding; ATF6; postnatal development; aging; heart 


\section{Abstract}

Cardiac myocyte death during heart failure is particularly detrimental, given that cardiac muscle exhibits limited regenerative potential. Protein aggregation was previously observed in end-stage heart failure, suggesting protein-misfolding in cardiac myocytes as a contributor to the disease process. However, the relationship between protein-misfolding, cardiac myocyte death, and myocardial dysfunction is yet to be clearly established. Here, we showed that protein synthesis and the unfolded protein response (UPR) declined as a function of mammalian postnatal development, especially in tissues with low mitotic activity, such as the heart. A deeper examination in animals models showed that compared to neonatal cardiac myocytes, adult cardiac myocytes expressed lower levels of the adaptive UPR transcription factor, ATF6, as well as lower levels of numerous ATF6regulated genes, which was associated with susceptibility to ER stress-induced cell death. Further reduction of the ATF6-dependent gene program in ATF6 knock-out mice led to the accumulation of misfolded proteins in the myocardium and impaired myocardial function in response to cardiac stress, indicating that ATF6 plays a critical adaptive role in the setting of cardiac disease. Thus, strategies to increase ATF6 aimed at balancing proteostasis in cardiac myocytes might be a fruitful avenue for the development of novel therapies for heart disease and other age-associated diseases. 
bioRxiv preprint doi: https://doi org/10.1101/2021.06.16.448596; this version posted June 16, 2021. The copyright holder for this preprint (which was not certified by peer review) is the author/funder, who has granted bioRxiv a license to display the preprint in perpetuity. It is made available under aCC-BY-NC-ND 4.0 International license.

\section{Highlights}

- The unfolded protein response (UPR) declines as a function of age in adult mammalian tissues with low mitotic activity, such as the heart

- Decreases in the UPR in adult cardiac myocytes is associated with impaired survival during ER stress

- ATF6 loss of function in adult hearts increases protein misfolding and cardiac disfunction during stress 


\section{Introduction}

Regulation of proteostasis is critical for maintaining a functional proteome and the prevention of toxic protein misfolding (Klaips et al., 2018). As organisms age, mechanisms for maintaining proteostasis are compromised, which limits the cellular capacity to sufficiently prevent protein misfolding during stress (Kaushik and Cuervo, 2015). This phenomenon has been studied for neurodegenerative diseases in which an age-associated decline in protein quality control and subsequent protein misfolding are major risk factors for disease development and progression (Hipp et al., 2019). The unfolded protein response (UPR) contributes to maintaining protein homeostasis (proteostasis) and was previously shown to decline with age in invertebrates (Ben-Zvi et al., 2009; Schindelin et al., 2012; Taylor and Dillin, 2013). However, whether the UPR declines with age in mammals, and if so, whether this decline contributes to pathology remains unresolved.

Proteostasis is especially important in tissues with low mitotic activity, such as the brain and heart, partly due to the lack of asymmetric inheritance of protein aggregates during cell division which can reduce the amount of misfolded proteins in the daughter cell (Aguilaniu et al., 2003; Hipp et al., 2019). Previously, protein aggregation has been observed during cardiac aging and in end-stage heart failure (Ayyadevara et al., 2016; Mohammed et al., 2014; Okada et al., 2004; Rainer et al., 2018; Sanbe et al., 2004; Tannous et al., 2008) and misfolded proteins are known to directly impair cardiac function (Hofmann et al., 2019; Pattison et al., 2008; Sanbe et al., 2004; Wang et al., 2001). However, whether an age-related decline of the UPR contributes to cardiac protein misfolding and impairs myocardial function during times of cardiac stress are not known.

In metazoans, the UPR initiates transcriptional and translational cellular reprogramming in response to ER stress. The three ER transmembrane proteins, inositol requiring enzyme $1 \alpha / \beta$ (IRE1) (Cox et al., 1993; Morl et al., 1993), PKR-like ER kinase (PERK) (Harding et al., 1999), and activating transcription factor $6 \alpha / \beta$ (ATF6) (Haze et al., 1999) regulate three branches of the UPR aimed at restoring proteostasis. ATF6 differs significantly from PERK and IRE1 in terms of its mechanism of activation. Upon accumulation of misfolded proteins, ATF6 transits to the Golgi apparatus where it is cleaved by site-specific proteases S1P and S2P (Haze et al., 1999; Shen et al., 2002). Active ATF6 translocates to the nucleus, where it serves as a potent and short-lived transcription factor, inducing adaptive proteins that restore ER folding capacity and resolve ER stress (Glembotski, 2014; Haze et al., 1999). Previously, ATF6 was shown to be essential for cardiac function, especially during 
bioRxiv preprint doi: https://doi org/10.1101/2021.06.16.448596; this version posted June 16, 2021. The copyright holder for this preprint (which was not certified by peer review) is the author/funder, who has granted bioRxiv a license to display the preprint in perpetuity. It is made available under aCC-BY-NC-ND 4.0 International license.

pathological conditions that are associated with proteotoxic stress, such as cardiac growth or reperfusion (Blackwood et al., 2019a; Jin et al., 2017; Martindale et al., 2006). Therefore, while it has not yet been studied, an age-related decline in the ATF6 branch of the UPR would be predicted to promote

myocardial

dysfunction. 


\section{Results}

\section{Impairment of UPR-mediated protein quality control as a function of age}

We first assessed the protein synthesis aspect of proteostasis, as well as the expression of several UPR-regulated gene products during postnatal development in different tissues in neonatal (one day old), young adult (10 weeks old), and middle-aged (52 weeks old) mice. To measure changes in protein synthesis rates, in vivo, mice were injected with puromycin. Detection of puromycin-labelled peptides by immunoblotting using an anti-puromycin antibody showed ageassociated decreases in protein synthesis rates in the tissues of low mitotic activity heart, skeletal muscle, and brain (Fig. 1A-C). While we observed a significant age-dependent reduction of protein synthesis in mitotic tissues such as kidney and liver, this reduction was less pronounced compared to that in tissues with low mitotic activity (Fig. 1D, E). We also found a reduced abundance of the canonical hallmark adaptive UPR-induced gene products, chaperones $78 \mathrm{kDa}$ glucose-regulated protein (GRP78) and GRP94, and protein disulfide-isomerase A6 (PDIA6), in young adult and middleaged mice tissues compared to neonatal, a reduction that was more pronounced in low-mitotic tissues (Fig. 1F-J). Importantly, we found a highly significant correlation between protein synthesis and UPR gene expression in all samples, which may indicate protein synthesis and the UPR are coordinately regulated (Fig. 1K).

\section{Reduced responsiveness of the UPR in the adult heart makes cardiac myocytes susceptible to proteotoxic stress}

To more broadly assess the pathophysiological importance of the UPR aspect of proteostasis in the heart as a function of age, we examined human heart from different ages ranging from newborn to adult (Cardoso-Moreira et al., 2019) for changes in the expression of canonical UPR genes during human postnatal development and aging. We observed an age-related decline in the expression of these UPR genes from young adulthood in human hearts (Fig. 2A).

While myocytes comprise more than $90 \%$ of the mass of the heart, they do not represent the dominant cell type, as about $70 \%$ of cardiac cells are nonmyocytes, such as endothelial cells and fibroblasts, which maintain the ability to divide throughout development (Pinto et al., 2016). Accordingly, to characterize the UPR in cardiac myocytes as a function of age we isolated ventricular myocytes from neonatal and adult rats. Similar to data from whole left ventricular lysates, protein 
synthesis and levels of adaptive UPR-regulated gene products decreased as a function of age in isolated cardiac myocytes (Fig. 2B; Fig. S1A, C). However, the decline in UPR gene expression was more pronounced in isolated cardiac myocytes compared to heart extracts, falling to nearly undetectable levels in cardiac myocytes of adult rats (Fig. 2B; Fig. S1A-C). While the protein glycosylation inhibitor, tunicamycin (TM) was able to induce UPR genes in adult cardiac myocytes (Fig. S2), UPR gene expression did not reach the levels of neonatal cardiac myocytes, even after TM treatment (Fig. 2B). Importantly, the decline of the UPR in adult cardiac myocytes was accompanied by impaired survival of adult cardiac myocytes in response to TM treatment (Fig. 2C), indicating that the reduced UPR responsiveness in adult cardiac myocytes is associated with impaired survival during ER stress. To assess the UPR on a global level, we examined the expression of genes downstream of the all three UPR branches, ATF6, PERK, and IRE1 during human postnatal development and aging (Cardoso-Moreira et al., 2019) and found a significant downregulation of ATF6 genes in mid-age in human heart (Fig. 2D-F).

Decline of ATF6 and the ATF6-regulated UPR gene program with age has negligible effects in the heart at baseline

Since we found that ATF6-dependent target genes decrease in mid-age in the human heart, we focused on the ATF6 branch of the UPR. We hypothesized that the reduced expression of ATF6 in young adult and middle-aged mice is at least partly responsible for the decreased expression of UPR target genes in the heart. ATF6 knockout (KO) mice develop normally throughout adulthood and exhibit no overt cardiac phenotype (Wu et al., 2007; Yamamoto et al., 2007), indicating that ATF6 is not essential for normal cardiac development and function under non-stressed conditions (Jin et al., 2017). We performed transcript profiling of hearts from ATF6 KO mice. The absence of ATF6 was confirmed by RT-PCR (Fig. 3A). While RNA-sequencing revealed that "Response to endoplasmic reticulum stress" was among the most regulated signaling pathways in adult ATF6 KO mouse hearts (Fig. 3B), only a few UPR genes were significantly affected in ATF6 KO hearts compared to WT hearts (Fig. 3C, D), which is in agreement with previous studies that showed no major consequence of ATF6 deficiency on cardiac myocyte survival or UPR gene expression under baseline conditions (Correll et al., 2019; Jin et al., 2017; Wu et al., 2007; Yamamoto et al., 2007). ATF6 controls the expression of target genes by binding cis-acting promoter elements, such as the ER stress response element (ERSE) (Yamamoto et al., 2004). However, activation of the IRE1 branch of the UPR results 
in the cytoplasmic RNA splicing of UXBP1 to spliced XBP1, which when translated generates a transcription factor that binds to the same and additional promoter elements (Yamamoto et al., 2004). Therefore, expression of ATF6 target genes during ATF6 deficiency might be affected by activation of XBP1. Indeed, pharmacological inhibition of ATF6 activation with PF-429242 rapidly induced XPB1 splicing (Fig. S3), indicating that ATF6 deficiency in cardiac myocytes may be at least partly compensated by IRE1 pathway activation. Taken together, reduced ATF6 expression during cardiac aging seems to be at least partly responsible for the reduced UPR capacity of adult cardiac myocytes.

\section{Importance of the ATF6 branch of the UPR in adult cardiac myocyte hypertrophy}

Various cardiac pathologies are associated with increased protein synthesis, most notably cardiac hypertrophy, in which the increased synthesis of new protein drives the hypertrophic growth of cardiac myocytes (Frey and Olson, 2003). Cardiac myocyte hypertrophy during pathology, while initially adaptive, can eventually lead to impaired ventricular relaxation, filling, and eventually cardiac failure (Frey and Olson, 2003; Hill and Olson, 2008; Tardiff, 2006). Previously it was shown that misfolded proteins accumulate during pathological cardiac hypertrophy, however it is not known which factors contribute to this accumulation, nor is it known whether misfolded proteins contribute to the morbidity of cardiac hypertrophy (Singh and Robbins, 2018). Therefore, we investigated the role of UPR and ATF6 in proteostasis in the setting of pathological cardiac myocyte hypertrophy.

We first analyzed the UPR on an integrated transcriptome, translatome, and proteome dataset of the adult myocardial gene response during cardiac hypertrophy (Doroudgar et al., 2019). Interestingly, a biological process component category analysis revealed that "protein folding" and "response to ER stress" were among the most regulated gene ontology terms in the early phase of cardiac hypertrophy in mouse hearts 2 days after transverse aortic constriction (TAC) (Fig. 4A-C), a common surgical model of pressure overload-induced cardiac hypertrophy (Rockman et al., 1991). Several genes that belong to the gene ontology groups "response to unfolded protein", "endoplasmic reticulum unfolded protein response", and "response to endoplasmic reticulum stress", which we merged into the term "unfolded protein response genes", were found to be strongly regulated both on the transcriptional and translational levels (Fig. 4D, E). A more in-depth analysis revealed that this group included genes that are regulated by all three branches of the UPR (Fig. S4, S5). The cardiac UPR was only mildly upregulated at 3 hours, peaked at 2 days, and declined again, especially at the transcriptional level at 2 weeks after TAC (Fig. S4, S5). To expand our profiling results, we analyzed 
the ATF6-mediated UPR in isolated adult cardiac myocytes during adrenergic stimulation-induced hypertrophy (Fig. 4F). Adult cardiac myocytes exhibited an increase of ATF6 levels after adrenergic stimulation (Fig. 4G) leading to an increased expression of ATF6 target genes in a dose-dependent manner (Fig. 4H-J). Similarly, at 2 days after TAC surgery, when protein synthesis was increased (Fig. 4K, L), protein levels of the ATF6 target genes GRP94, GRP78, and PDIA6 were found significantly upregulated (Fig. 4M). Taken together, these results indicate that the UPR is upregulated during early phases of pathological hypertrophic growth in cardiac myocytes of the adult heart.

\section{Induction of the ATF6-mediated UPR is necessary to prevent protein misfolding during adult cardiac hypertrophy}

After establishing that ATF6 is activated in cardiac myocytes during cellular growth, we examined the involvement of ATF6 in cardiac hypertrophy. Inhibition of ATF6 in neonatal cardiac myocytes by siRNA-mediated knock-down attenuated neonatal cardiac myocyte hypertrophy in response to PE (Fig. 5A, B). Next, adult WT and ATF6 KO mice were subjected to implantation of isoproterenol (ISO)-loaded osmotic mini pumps or TAC surgery, two in vivo models of cardiac hypertrophy, and examined after 7 days, at a time point when cardiac protein synthesis and hypertrophic growth reach maximum (Wang et al., 2017). ISO and TAC both increased heart weight of WT mice, an effect that was impaired in ATF6 KO mice (Fig. 5C, E). Additionally, cardiac function, assessed by transthoracic echocardiography, was significantly impaired at 7 days in ATF6 KO mice, a time point when cardiac function remains preserved in WT mice (Supp. Table I, II; Fig. 5D, F) (Takaoka et al., 2002). ATF6 KO hearts from ISO-treated mice showed increased expression of pathologic cardiac remodeling marker genes Nppa, Nppb, Myh7, and Col1a1 and lower transcript levels of the $\mathrm{Ca}^{2+}$ handling gene product Atp2a2, compared to WT hearts (Fig. 5G, H). These markers of pathologic cardiac remodeling were not significantly different in ATF6 KO mice compared to WT mice after TAC surgery (Fig. 5G, H). To examine whether changes in the functional outcome of ATF6 KO mice are due to the loss of ATF6 transcriptional activity and its adaptive gene program, we expressed an adenovirus encoding a dominant negative form of ATF6, dnATF6 (Thuerauf et al., 2001). Furthermore, PF-429242, a chemical inhibitor of ATF6 activation was examined. Both dnATF6 and PF-429242 significantly reduced cardiac myocyte hypertrophy (Fig. 5I-K).

Finally, we examined the mechanisms of the blunted cardiac hypertrophic growth response and subsequent myocardial dysfunction in ATF6 KO mice. Cardiac hypertrophy was coupled with 
ATF6 activation after TAC surgery, as evidenced by the formation of the active 50kD ATF6, which was completely absent in ATF6 KO mice subjected to TAC surgery (Fig. 6A). Importantly, ATF6 KO hearts did not upregulate key UPR protein quality control regulators in response to ISO or TAC, indicating that ATF6 is necessary for UPR induction during cardiac stress (Fig. 6B, C). Together with the impaired activation of the UPR, ATF6 mice accumulated poly-ubiquitylated proteins 7 days after TAC surgery, a phenomenon that was only marginally observed in WT mice (Fig. 6D). Therefore, we investigated whether cardiac protein misfolding can be directly detected 7 days after TAC surgery when protein synthesis and hypertrophic growth reach maximum. We used immunoblotting with $A 11$, an antibody that detects a common epitope of soluble amyloid oligomers, the entity that is thought to at least partly constitute the pathogenic species of misfolded proteins in cardiac disease (Wang and Robbins, 2006). We observed the accumulation of A11-positive staining in the early phase of TACinduced cardiac hypertrophy but not in control, sham WT mice (Fig. 6E). While ATF6 KO mice did not exhibit detectible misfolded protein aggregates under baseline conditions, amyloid oligomers were increased in ATF6 KO mice after TAC surgery (Fig. 6E), demonstrating that ATF6 is essential for preventing the accumulation of misfolded proteins during the early phase of cardiac hypertrophy when protein synthesis is increased but myocardial function is still preserved. This suggests that the accumulation of misfolded proteins occurs during cardiac disease progression, supporting the notion that misfolded proteins are a cause of cardiac dysfunction, not a consequence. 


\section{Discussion}

In invertebrates the decline in protein homeostasis declines as a function of age in invertebrates contributes to disease-like phenotypes (Kikis et al., 2010). However, analyses of the proteostasis network in aging mammals are limited (Kaushik and Cuervo, 2015). Here, we investigated protein synthesis and UPR-mediated protein quality control capacity during postnatal development and aging in mice and rats. We observed coordinate decreases of the ATF6 branch of the UPR and protein synthesis as a function of age, especially in postmitotic organs, such as the heart. A focused examination of the heart revealed that the decline of the UPR renders adult cardiac myocytes more susceptible to proteotoxic stress, which was at least partly attributable to decreased activity of the ATF6 branch of the UPR. Decreased ATF6 activation, as might occur in the aging human population, attenuated the adaptive cardiac hypertrophic growth response to stress and fostered protein misfolding and cardiac dysfunction, highlighting the importance of the UPR for myocardial function in the adult and aging heart during cardiac stress.

\section{Decrease of the UPR during postnatal development in tissues with low mitotic activity}

In many age-related diseases the dysfunction of protein homeostasis leads to the accumulation of misfolded proteins. Moreover, interventions that strengthen the proteostasis network extend the lifespan of invertebrates and mammals and suppresses age-related diseases (Eisenberg et al., 2016; Harrison et al., 2009; Kaushik and Cuervo, 2015; Labbadia and Morimoto, 2014). The proteostasis network in the ER, known as the unfolded protein response (UPR) is activated by ER protein misfolding. Upon activation, the UPR initiates signaling to restore proteostasis and other disrupted cellular conditions, such as metabolic homeostasis or redox status (Han and Kaufman, 2017; Hetz and Papa, 2018). Several studies showed that activation of the UPR promotes longevity in yeast, C. elegans, and Drosophila (Burkewitz et al., 2020; Chen et al., 2009; Henis-Korenblit et al., 2010; Kaushik and Cuervo, 2015; Labunskyy et al., 2014; Matai et al., 2019; Sekiya et al., 2017; Shore et al., 2012). Most of these studies were performed in invertebrates and examinations of the proteostasis network during mammalian aging are limited. Recent studies in $C$. elegans have indicated that the collapse of proteostasis is a programmed event that occurs at an early stage of adulthood (Ben-Zvi et al., 2009; David et al., 2010; Labbadia and Morimoto, 2014). To investigate whether a collapse of ER proteostasis occurs as a function of age in mammals, we evaluated the UPR and protein synthesis capacity of neonatal (7 days), young adult (10 weeks), and middle-aged (52 weeks) 
mice for different mitotic and low-mitotic tissues. Similar to invertebrates, both the UPR and protein synthesis were decreased in young adult mice, especially in tissues with low mitotic activity. Additionally, cardiac gene expression data indicated that the expression of some UPR genes is also reduced in humans as a function of age. One possibility for the reduction of the proteostasis network is that high rates of protein synthesis, which are necessary for rapid cellular differentiation early in life and during cell division, is non-essential as cardiac myocytes enter senescence in the adult heart, leading to diminished proteostasis and a new equilibrium later in life (Eisenberg et al., 2016). Indeed, mitotic tissues that have a high protein synthesis capacity throughout life, such as the liver, retained high levels of the UPR with only a minor reduction throughout adulthood, whereas low-mitotic tissues showed a drastic reduction in protein synthesis and the UPR. A recent study showed that the attenuation of protein synthesis in hematopoietic stem cells increases proteome quality (Hidalgo San Jose et al., 2020), most likely by fostering an adaptive balance between protein synthesis and the UPR. However, whether this occurs in other mammalian tissues remains largely unresolved. Moreover, whether age-related decreases of protein synthesis in adult and aged mammals is a secondary response to an impaired proteostasis, or whether other events trigger the downregulation of protein synthesis and the proteostasis network, remain unknown.

\section{Responsiveness of the UPR to proteotoxic stress is impaired in adult cardiac myocytes}

A reduced proteostasis network in and of itself may not be pathogenic, if it can be increased in response to cellular stress. However, previous studies in $C$. elegans showed that induction of the heat shock response and the UPR is largely compromised after early adulthood (Ben-Zvi et al., 2009; Taylor and Dillin, 2013). While the induction of the UPR was compromised in adult hearts in our study, ATF6 insufficiency did not majorly affect cell survival and UPR expression under baseline conditions in adult hearts, which is coordinate with previous reports (Blackwood et al., 2019a; Correll et al., 2019; Jin et al., 2017). Therefore, ATF6, appears to act primarily as a stress transcription factor in the adult heart, which can be activated by different stimuli, albeit to lower levels than during younger age.

\section{Loss of ATF6 leads to the accumulation of misfolded proteins in the myocardium and cardiac}

\section{dysfunction}

Recent studies have shed light on the involvement of proteostasis-related signaling pathways in cardiac diseases. However, quite surprisingly, relatively little is known about when, and to what extent protein misfolding occurs in the heart, and whether it significantly contributes to heart disease 
(Singh and Robbins, 2018). Much of our understanding of the involvement of misfolded proteins in cardiac disease arises from studies of desmin-related (cardio)myopathy, a heterogeneous group of human myopathies which are characterized by the presence of large amounts of intra-sarcoplasmic protein aggregates (Wang and Robbins, 2006). However, even in those cardiomyopathies it remains the subject of ongoing investigation as to whether aggregates are inherently toxic and contribute to myocardial dysfunction or whether they may even be protective (McLendon and Robbins, 2015). Recent findings indeed suggest that the cytotoxic source of misfolded protein are soluble pre-amyloid oligomers, protofibrils, and other intermediates in the amyloid fibril pathway (Singh and Robbins, 2018). Moreover, whether protein misfolding contributes to other cardiac diseases remains to be shown (Singh and Robbins, 2018).

Enhancing protein quality control pathways protects from cardiac disease and protein misfolding (Bhuiyan et al., 2013; Blackwood et al., 2019b; Hofmann et al., 2019; Lynch et al., 2012; Schiattarella et al., 2019; Wang and Robbins, 2006; Yao et al., 2017). Here, we found activation of the ATF6 branch of the UPR in response to acute pressure overload, similar to previous reports (Blackwood et al., 2019a; Lynch et al., 2012). In addition, we showed that protein misfolding can occur in the early phases of heart disease even before cardiac function is compromised. We also showed that UPR is compromised upon early adulthood in the heart. However, in the adult heart, UPR activation was sufficient to protect against protein misfolding and cardiac dysfunction. Nonetheless, it is known that the proteostasis network can collapse during continuous proteotoxic stress, or in aging (Labbadia and Morimoto, 2015). Therefore, it is possible that ongoing proteotoxic stress results in the collapse of the proteostasis network in the adult heart, which may contribute to cardiac disease progression. This would be coordinate with previous studies which found misfolded proteins in (endstage) heart failure and preclinical studies which showed that enhancing the proteostasis network protects against cardiac diseases. However, this concept remains to be examined in future studies in animal models and humans.

in summary, this study provides insights into the status and functions of the UPR during mammalian postnatal development and the contribution of the ATF6 branch of the UPR to adult myocardial function during cardiac stress. Insufficient UPR activation, due to decreases in ATF6 induced protein misfolding, diminished the hypertrophic cardiac growth response, and impaired myocardial function in response to cardiac stress. Our study suggests that increasing the UPR and, 
bioRxiv preprint doi: https://doi.org/10.1101/2021.06.16.448596; this version posted June 16, 2021. The copyright holder for this preprint (which was not certified by peer review) is the author/funder, who has granted bioRxiv a license to display the preprint in perpetuity. It is made available under aCC-BY-NC-ND 4.0 International license.

specifically, increasing or activating ATF6 might be a promising strategy to target proteotoxicity-driven heart disease and contributes to the growing body of evidence that protein misfolding directly contributes to cardiac disease progression. 


\section{Methods}

\section{Key Resources Table}

\begin{tabular}{|c|c|c|}
\hline REAGENT or RESOURCE & SOURCE & IDENTIFIER \\
\hline \multicolumn{3}{|l|}{ Antibodies } \\
\hline Mouse monoclonal anti-Puromycin, clone 12D10 & Sigma-Aldrich & $\begin{array}{l}\text { Cat\# MABE343; } \\
\text { RRID: } \\
\text { AB 2566826 }\end{array}$ \\
\hline Mouse monoclonal anti-KDEL & ENZO Life Sciences & $\begin{array}{l}\text { Cat\# 10C3; RRID: } \\
\underline{\text { AB } 10618036}\end{array}$ \\
\hline Rabbit polyclonal anti-ATF6 & Proteintech & $\begin{array}{l}\text { Cat\# 24169-1-AP; } \\
\text { RRID: } \\
\text { AB } 2876891\end{array}$ \\
\hline Mouse monoclonal anti- $\beta$-Actin & $\begin{array}{l}\text { Santa Cruz } \\
\text { Biotechnology }\end{array}$ & $\begin{array}{l}\text { Cat\# sc-47778; } \\
\text { RRID: } \underline{\text { AB } \quad 626632}\end{array}$ \\
\hline $\begin{array}{l}\text { Mouse monoclonal anti-Ubiquitinylated proteins,clone } \\
\text { FK2 }\end{array}$ & Sigma-Aldrich & $\begin{array}{l}\text { Cat\# 04-263; RRID: } \\
\underline{\text { AB } 612093}\end{array}$ \\
\hline Mouse monoclonal anti-GAPDH (G-9) & $\begin{array}{l}\text { Santa Cruz } \\
\text { Biotechnology }\end{array}$ & $\begin{array}{l}\text { Cat\# sc-365062; } \\
\text { RRID: } \\
\text { AB } 10847862 \\
\end{array}$ \\
\hline Mouse monoclonal anti-a-Actinin (Sarcomeric) & Sigma-Aldrich & $\begin{array}{l}\text { Cat\# A7811; RRID: } \\
\underline{\text { AB } 476766}\end{array}$ \\
\hline Mouse monoclonal anti-tropomyosin & Sigma-Aldrich & $\begin{array}{l}\text { Cat\# T9283; RRID: } \\
\text { AB } 261817\end{array}$ \\
\hline A11 & Vector Laboratories, & Cat\# BA-1000 \\
\hline $\begin{array}{l}\text { Donkey polyclonal Fluorescein (FITC)-conjugated } \\
\text { AffiniPure Donkey Anti-Mouse IgG }\end{array}$ & $\begin{array}{l}\text { Jackson Immuno } \\
\text { Research }\end{array}$ & $\begin{array}{l}\text { Cat\# 715-095-151; } \\
\text { RRID: } \\
\text { AB 2335588 }\end{array}$ \\
\hline $\begin{array}{l}\text { Donkey polyclonal Cy3-conjugated AffiniPure Donkey } \\
\text { Anti-Mouse IgG }\end{array}$ & $\begin{array}{l}\text { Jackson Immuno } \\
\text { Research }\end{array}$ & $\begin{array}{l}\text { Cat\# 715-165-151; } \\
\text { RRID: } \\
\text { AB } 2315777\end{array}$ \\
\hline \multicolumn{3}{|l|}{ Bacterial and virus strains } \\
\hline AAV9 Control & (Jin et al., 2017) & $\bar{N} / \mathrm{A}$ \\
\hline AAV9 dnATF6a & (Thuerauf et al., 2001) & $\mathrm{N} / \mathrm{A}$ \\
\hline
\end{tabular}




\begin{tabular}{|c|c|c|}
\hline \multicolumn{3}{|l|}{ Chemicals, peptides, and recombinant proteins } \\
\hline Ponceau BS & Sigma-Aldrich & Cat\# B6008 \\
\hline Fibronectin bovine plasma & Sigma-Aldrich & Cat\# F1141 \\
\hline DMEM/F-12, HEPES & $\begin{array}{l}\text { Thermo Fisher } \\
\text { Scientific }\end{array}$ & Cat\# 11330032 \\
\hline Medium 199 & Sigma-Aldrich & Cat\# M7528 \\
\hline DPBS, no calcium, no magnesium & $\begin{array}{l}\text { Thermo Fisher } \\
\text { Scientific }\end{array}$ & Cat\# 14190144 \\
\hline Penicillin-Streptomycin-Glutamine (100X) & $\begin{array}{l}\text { Thermo Fisher } \\
\text { Scientific }\end{array}$ & Cat\# 10378016 \\
\hline Laminin & Sigma-Aldrich & Cat\# L2020 \\
\hline HiPerFect Transfection Reagent & QIAGEN & Cat\# 301704 \\
\hline PF-429242 dihydrochloride & Sigma-Aldrich & Cat\# SML0667 \\
\hline (R)-(-)-Phenylephrine hydrochloride & Sigma-Aldrich & Cat\# P6126 \\
\hline (-)-Isoproterenol -hydrochlorid & Sigma-Aldrich & Cat\# I6504 \\
\hline Propidium lodide & $\begin{array}{l}\text { Thermo Fisher } \\
\text { Scientific }\end{array}$ & Cat\# P21493 \\
\hline Hoechst 33342, Trihydrochloride, Trihydrate & $\begin{array}{l}\text { Thermo Fisher } \\
\text { Scientific }\end{array}$ & Cat\# H21492 \\
\hline Tunicamycin & Sigma-Aldrich & Cat\# T7765 \\
\hline Protease inhibitor cOmplete ULTRA & Roche & Cat\# 5892791001 \\
\hline PhosSTOP & Sigma-Aldrich & Cat\# 04906837001 \\
\hline 4x Laemmli Sample Buffer & Bio-Rad & Cat\# 1610747 \\
\hline 2-Mercaptoethanol & Sigma-Aldrich & Cat\# M6250 \\
\hline ALLN & Sigma-Aldrich & Cat\# 208719 \\
\hline Critical commercial assays & & \\
\hline RNeasy Mini Kit & QIAGEN & Cat\# 74104 \\
\hline Quick-RNA MiniPrep Kit & Zymo Research & Cat\# R1055 \\
\hline DC Protein Assay Kit II & Bio-Rad & Cat\# 5000112 \\
\hline Superscript III First-Strand Synthesis System & Invitrogen & Cat\# 18080051 \\
\hline
\end{tabular}


bioRxiv preprint doi: https://doi.org/10.1101/2021.06.16.448596; this version posted June 16, 2021. The copyright holder for this preprint (which was not certified by peer review) is the author/funder, who has granted bioRxiv a license to display the preprint in perpetuity. It is made available under aCC-BY-NC-ND 4.0 International license.

\begin{tabular}{|c|c|c|}
\hline Maxima SYBR Green/ROX qPCR Master Mix & $\begin{array}{l}\text { Thermo Fisher } \\
\text { Scientific }\end{array}$ & Cat\# K0221 \\
\hline \multicolumn{3}{|l|}{ Deposited data } \\
\hline Raw and analyzed data & This paper & $\mathrm{N} / \mathrm{A}$ \\
\hline $\begin{array}{l}\text { Mouse reference genome GRCm39, Ensembl release } \\
102\end{array}$ & Ensembl & $\begin{array}{l}\text { http://www.ensembl. } \\
\text { org/Mus_musculus/l } \\
\text { nfo/Index }\end{array}$ \\
\hline $\begin{array}{l}\text { Cardiomyocyte-specific RNA-Seq and ribosome profiling } \\
\text { gene expression data from hearts after TAC } 3 \text { hours, } 2 \\
\text { days and } 2 \text { weeks }\end{array}$ & $\begin{array}{l}\text { (Doroudgar et al., } \\
\text { 2019) }\end{array}$ & $\begin{array}{l}\text { SRA: PRJNA484227 } \\
\text { https://www.ncbi.nlm } \\
\text {.nih.gov/sra/?term=P } \\
\text { RJNA484227 }\end{array}$ \\
\hline ATF6 and XBP1s target genes & $\begin{array}{l}\text { (Shoulders et al., } \\
\text { 2013) }\end{array}$ & Data supplements \\
\hline PERK target genes & (Lu et al., 2004) & Data supplements \\
\hline \multicolumn{3}{|l|}{ Experimental models: organisms/strains } \\
\hline Rat: WISTAR, HanRj:WI Rattus norvegicus & Janvier Labs & $\begin{array}{l}\text { Cat\# 13792727; } \\
\text { RRID: } \\
\text { RGD_13792727 }\end{array}$ \\
\hline Mouse: C57BL/6JRj & Janvier Labs & $\begin{array}{l}\text { MGI Cat\# 2670020; } \\
\text { RRID:MGI:2670020 }\end{array}$ \\
\hline Mouse: ATF6a KO & (Wu et al., 2007) & $\mathrm{N} / \mathrm{A}$ \\
\hline \multicolumn{3}{|l|}{ Oligonucleotides } \\
\hline $\begin{array}{l}\text { Rat ATF6a Stealth siRNA: } \\
\text { GCUCUCUUUGUUGUUGCUUAGUGGA }\end{array}$ & Thermo Fisher & ID\# RSS315363 \\
\hline Rat siRNA Negative Control & Thermo Fisher & Cat\# 12935300 \\
\hline \multicolumn{3}{|l|}{ Real-time PCR primers } \\
\hline Mouse-Atf6-F: ATGGCCATGCTGGTCTATG & This paper & $\mathrm{N} / \mathrm{A}$ \\
\hline $\begin{array}{l}\text { Mouse-Atf6-R: CTGGTTGGGAAAGACATCTTCTA } \\
\text { Mouse-Atp2a2-F: CCAGAGAGATGCCTGCTTAAA }\end{array}$ & $\begin{array}{l}\text { This paper } \\
\text { (Blackwood et al., } \\
\text { 2019b) }\end{array}$ & $\begin{array}{l}\mathrm{N} / \mathrm{A} \\
\mathrm{N} / \mathrm{A}\end{array}$ \\
\hline Mouse-Atp2a2-R: CACGTTGGATGAGATGAGGTAG & $\begin{array}{l}\text { (Blackwood et al., } \\
\text { 2019b) }\end{array}$ & $\mathrm{N} / \mathrm{A}$ \\
\hline
\end{tabular}




\begin{tabular}{|c|c|c|}
\hline Mouse- $\beta$-Actin-F: GACGGCCAGGTCATCACTAT & $\begin{array}{l}\text { (Blackwood et al., } \\
\text { 2019b) }\end{array}$ & $\mathrm{N} / \mathrm{A}$ \\
\hline Mouse- $\beta$-Actin-R: GTACTTGCGCTCAGGAGGAG & $\begin{array}{l}\text { (Blackwood et al., } \\
\text { 2019b) }\end{array}$ & $\mathrm{N} / \mathrm{A}$ \\
\hline Mouse-Col1a1-F: GAAGCACGTCTGGTTTGGA & $\begin{array}{l}\text { (Blackwood et al., } \\
\text { 2019b) }\end{array}$ & $\mathrm{N} / \mathrm{A}$ \\
\hline Mouse-Col1a1-R: ACTCGAACGGGAATCCATC & $\begin{array}{l}\text { (Blackwood et al., } \\
\text { 2019b) }\end{array}$ & $\mathrm{N} / \mathrm{A}$ \\
\hline Mouse-Hsp90b1-F: TCGTCAGAGCTGATGATGAAGT & This paper & $\mathrm{N} / \mathrm{A}$ \\
\hline Mouse-Hsp90b1-R: GCGTTTAACCCATCCAACTGAAT & This paper & $\mathrm{N} / \mathrm{A}$ \\
\hline $\begin{array}{l}\text { Mouse-Hspa5-F: CACGTCCAACCCCGAGAA } \\
\text { Mouse-Hspa5-R: ATTCCAAGTGCGTCCGATG }\end{array}$ & $\begin{array}{l}\text { This paper } \\
\text { This paper }\end{array}$ & $\begin{array}{l}\text { N/A } \\
\text { N/A }\end{array}$ \\
\hline Mouse-Manf-F: TGGGTGCGTTCTTCGACAT & This paper & $\mathrm{N} / \mathrm{A}$ \\
\hline Mouse-Manf-R: GACGGTTGCTGGATCATTGAT & This paper & $\mathrm{N} / \mathrm{A}$ \\
\hline Mouse-Myh7-F: TGCCCGATGACAAAGAAGAG & $\begin{array}{l}\text { (Blackwood et al., } \\
\text { 2019b) }\end{array}$ & $\mathrm{N} / \mathrm{A}$ \\
\hline Mouse-Myh7-R: AAGAGGCCCGAGTAGGTATAG & $\begin{array}{l}\text { (Blackwood et al., } \\
\text { 2019b) }\end{array}$ & $\mathrm{N} / \mathrm{A}$ \\
\hline Mouse-Nppa-F: GAGAGAGAGAAAGAAACCAGAGTG & $\begin{array}{l}\text { (Blackwood et al., } \\
\text { 2019b) }\end{array}$ & $\mathrm{N} / \mathrm{A}$ \\
\hline Mouse-Nppa-R: CTCATCTTCTACCGGCATCTTC & $\begin{array}{l}\text { (Blackwood et al., } \\
\text { 2019b) }\end{array}$ & $\mathrm{N} / \mathrm{A}$ \\
\hline Mouse-Nppb-F: GTCAGTCGTTTGGGCTGTAA & $\begin{array}{l}\text { (Blackwood et al., } \\
\text { 2019b) }\end{array}$ & $\mathrm{N} / \mathrm{A}$ \\
\hline Mouse-Nppb-R: GCAAGTTTGTGCTCCAAGATAAG & $\begin{array}{l}\text { (Blackwood et al., } \\
\text { 2019b) }\end{array}$ & $\mathrm{N} / \mathrm{A}$ \\
\hline Mouse-Pdia6-F: TGCCACCATGAATCAGGTTCT & This paper & $\mathrm{N} / \mathrm{A}$ \\
\hline Mouse-Pdia6-R: TCGTCCGACCACCATCATAGT & This paper & $\mathrm{N} / \mathrm{A}$ \\
\hline Mouse-Syvn1-F: CCAACATCTCCTGGCTCTTCCA & This paper & $\mathrm{N} / \mathrm{A}$ \\
\hline Mouse-Syvn1-R: CAGGATGCTGTGATAAGCGTGG & This paper & $\mathrm{N} / \mathrm{A}$ \\
\hline Rat-18S-F: CGAGCCGCCTGGATACC & This paper & \\
\hline Rat-18S-R: CATGGCCTCAGTTCCGAAAA & This paper & \\
\hline
\end{tabular}




\begin{tabular}{|c|c|c|}
\hline Rat-Atf6-F: CTTCCTCCAGTTGCTCCATC & This paper & $\mathrm{N} / \mathrm{A}$ \\
\hline Rat-Atf6-R: CAACTCCTCAGGAACGTGCT & This paper & $\mathrm{N} / \mathrm{A}$ \\
\hline Rat-Gapdh-F: GACAAACGTCTTCGGGAATTG & This paper & $\mathrm{N} / \mathrm{A}$ \\
\hline Rat-Gapdh-R: CTCTTTAAGGGCAGGGAGTATC & This paper & $\mathrm{N} / \mathrm{A}$ \\
\hline Rat-Hsp90b1-F: AAGCATCTGATTACCTTGAATTGGAT & This paper & $\mathrm{N} / \mathrm{A}$ \\
\hline Rat-Hsp90b1-R: CTCCTCCACAGTCTCAGTCTTGCT & This paper & $\mathrm{N} / \mathrm{A}$ \\
\hline Rat-Hspa5-F: CACGTCCAACCCGGAGAA & This paper & $\mathrm{N} / \mathrm{A}$ \\
\hline Rat-Hspa5-R: GTAGCCTGCGTGAACCTTA & This paper & $\mathrm{N} / \mathrm{A}$ \\
\hline Rat-Pdia6-F: GGTGAAATTGGCAGCCGTA & This paper & $\mathrm{N} / \mathrm{A}$ \\
\hline Rat-Pdia6-R: CAGGAGACTCGCCTTTCTGAA & This paper & $\mathrm{N} / \mathrm{A}$ \\
\hline Rat-Xbp1-F: ACGAGAGAAAACTCATGGGC & This paper & $\mathrm{N} / \mathrm{A}$ \\
\hline Rat-Xbp1-R: ACAGGGTCCAACTTGTCCAG & This paper & $\mathrm{N} / \mathrm{A}$ \\
\hline \multicolumn{3}{|l|}{ Software and algorithms } \\
\hline FIJI (ImageJ) & $\begin{array}{l}\text { (Rueden et al., 2017; } \\
\text { Schindelin et al., } \\
2012 \text { ) }\end{array}$ & https://fiji.sc \\
\hline Prism v7.0 & GraphPad & $\begin{array}{l}\text { https://www.graphpa } \\
\text { d.com/scientific- } \\
\text { software/prism/ }\end{array}$ \\
\hline Adobe Illustrator & Adobe & $\begin{array}{l}\text { https://www.adobe.c } \\
\text { om/products/illustrat } \\
\text { or.html }\end{array}$ \\
\hline $\mathrm{R}$ & R Foundation & $\begin{array}{l}\text { https://www.r- } \\
\text { project.org }\end{array}$ \\
\hline R studio & R studio & https://rstudio.com/ \\
\hline Flexbar v3.0.315 & (Roehr et al., 2017) & $\begin{array}{l}\text { https://github.com/se } \\
\text { qan/flexbar }\end{array}$ \\
\hline Bowtie2 v2.3.0 & $\begin{array}{l}\text { (Langmead and } \\
\text { Salzberg, 2012) }\end{array}$ & $\begin{array}{l}\text { http://bowtie- } \\
\text { bio.sourceforge.net/ } \\
\text { bowtie2/index.shtml }\end{array}$ \\
\hline STAR aligner, v2.5.3a17 & (Dobin et al., 2013) & $\begin{array}{l}\text { https://github.com/al } \\
\text { exdobin/STAR }\end{array}$ \\
\hline
\end{tabular}




\begin{tabular}{|c|c|c|}
\hline Rsubread v1.24.218 & (Liao et al., 2019) & $\begin{array}{l}\text { https://bioconductor. } \\
\text { org/packages/releas } \\
\text { e/bioc/html/Rsubrea } \\
\text { d.html }\end{array}$ \\
\hline edgeR v3.32.1 & (Robinson et al., 2010) & $\begin{array}{l}\text { https://bioconductor. } \\
\text { org/packages/releas } \\
\text { e/bioc/html/edgeR.ht } \\
\text { ml }\end{array}$ \\
\hline DAVID v6.8 & $\begin{array}{l}\text { (Dennis et al., 2003; } \\
\text { Huang et al., 2009) }\end{array}$ & $\begin{array}{l}\text { https://david.ncifcrf.g } \\
\text { ov }\end{array}$ \\
\hline \multicolumn{3}{|l|}{ Other } \\
\hline ALZET mini-osmotic pump (Model 1007D) & ALZET & Cat\# 0000290 \\
\hline Immobilon-P Membrane & Merck Millipore & Cat\# IPVH00010 \\
\hline
\end{tabular}

\section{Resource availability}

\section{Lead contact}

Further information and requests for resources and reagents should be directed to and will be fulfilled by the lead contact, Shirin Doroudgar (sdoroudgar@arizona.edu).

\section{Materials availability}

This study did not generate new unique reagents.

\section{Data and code availability statement}

The raw sequencing data generated during this study is available in the NCBI SRA under BioProject ID PRJNA735269. Code used for data analyses is available at https://github.com/jakobilab/Hofmann et al 2021.

\section{Experimental model and subject details}

\section{Laboratory animals}

Data associated with all animal studies reported in this article has been reviewed and approved by the institutional animal care and use committee and conforms to the guide for the care and use of laboratory animals published by the National Research Council. All experiments were performed in 7 day, 10-week and 52-week-old male mice unless otherwise indicated. WT mice used for experiments 
in which no comparison to ATF6 KO mice was performed were purchased from Jackson Laboratory (Jackson Stock No: 005304). In agreement with previous reports, ATF6 deletion did not affect mouse development (Blackwood et al., 2019a; Jin et al., 2017; Wu et al., 2007). In addition, we did not observe any gender differences on the effects of ATF6 on cardiac structure and function in mice. Due to these observations, and in an attempt to decrease the total number of mice needed to adequately power the study, only male mice were used. All animals were fed ad libitum and were housed in a temperature- and humidity-controlled facility with a 12-h light-dark cycle. In the experiments where Puromycin was used to determine protein synthesis rate in vivo, 40mg/kg of puromycin diluted in PBS was given via intraperitoneal injection 30 minutes before animals were sacrificed.

\section{Cultured neonatal rat cardiac myocytes (NRVMs)}

Isolation of neonatal rat ventricular cardiac myocytes was performed as previously described (Jin et al., 2017). Cells were isolated from one to two-day old Wistar rats (cat\# 13792727, WISTAR HanRj:WI, Janvier Labs) via enzymatic digestion and purified by Percoll density gradient centrifugation. Cardiac myocytes were then plated at a density of $0.5 \times 10^{6}$ cells per well on $34.8 \mathrm{~mm}$ plastic plates that had been pre-treated with $5 \mu \mathrm{g} / \mathrm{mL}$ fibronectin (cat\# F1141, Sigma-Aldrich) in serum free DMEM/F12 medium (cat\# 11330032, Thermo Fisher Scientific) for one hour and then cultured in DMEM/F12 1:1, containing $10 \%$ fetal bovine serum, 100 units $/ \mathrm{mL}$ of penicillin, $100 \mu \mathrm{g} / \mathrm{mL}$ streptomycin and $292 \mu \mathrm{g} / \mathrm{mL}$ glutamine (cat\# 10378016, Thermo Fisher Scientific). After 24h, media was changed to DMEM/F12 1:1 supplemented with BSA (1 mg/mL), 100 units $/ \mathrm{mL}$ of penicillin, $100 \mu \mathrm{g} / \mathrm{mL}$ streptomycin and $292 \mu \mathrm{g} / \mathrm{mL}$ glutamine or when neonatal cardiac myocytes were directly compared to adult cardiac myocytes to DMEM/F12 $1: 1$, containing only 100 units $/ \mathrm{mL}$ of penicillin, $100 \mu \mathrm{g} / \mathrm{mL}$ streptomycin and $292 \mu \mathrm{g} / \mathrm{mL}$ glutamine for $24 \mathrm{~h}$ after which the cells were subjected to the respective treatments.

\section{Cultured adult rat ventricular cardiac myocytes (ARVMs)}

Adult rat ventricular myocytes were isolated from 6-week old male Wistar rats (WISTAR RjHan:WI, Janvier Labs) via enzymatic digestion as previously described (Jin et al., 2017; Völkers et al., 2011). Hearts were rapidly excised and perfused with a rate of $8 \mathrm{~mL} / \mathrm{min}$ in a Langendorff apparatus. After excision, hearts were initially perfused with calcium-free medium (ACM) (pH 7.2) consisting of (in mM) $5.4 \mathrm{KCl}, 3.5 \mathrm{MgSO} 4,0.05$ pyruvate, $20 \mathrm{NaHCO}$, 11 glucose, 20 HEPES, 23.5 glutamate, 4.87 acetate, 10 EDTA, 0.5 phenol red, 15 butanedionemonoxime (BDM), 20 creatinine, 15 creatine 
phosphate (CrP), 15 taurine and 27 units $/ \mathrm{mL}$ insulin under continuous equilibrium with $95 \% \mathrm{O} 2$ and $5 \%$ CO2. After $5 \mathrm{~min}$ the perfusion was switched to ACM plus collagenase $(0.5 \mathrm{U} / \mathrm{mL})$ for $20-30 \mathrm{~min}$. Finally, perfusion was changed to low $\mathrm{Na}+$, high sucrose Tyrode solution containing (in $\mathrm{mM}$ ) 52.5 $\mathrm{NaCl}, 4.8 \mathrm{KCl}, 1.19 \mathrm{KH} 2 \mathrm{PO} 4,1.2 \mathrm{MgSO} 4,11.1$ glucose, 145 sucrose, 10 taurine, $10 \mathrm{HEPES}, 0.2$ $\mathrm{CaCl} 2$ for $15 \mathrm{~min}$. Thereafter left ventricles of digested hearts were cut into small pieces and subjected to gentle agitation to allow for dissociation of cells. Consequently, cells were resuspended in ACM without BDM in which $2 \mathrm{mM}$ extracellular calcium was gradually reintroduced at $25^{\circ} \mathrm{C}$. ARVMs were cultured on laminin coated culture dishes. Cells were plated in Medium 199 (cat\# M7528, SigmaAldrich) supplemented with 100 units $/ \mathrm{mL}$ of penicillin, $100 \mu \mathrm{g} / \mathrm{mL}$ streptomycin and $10 \mu \mathrm{g} / \mathrm{mL}$ laminin (cat\# L2020, Sigma-Aldrich). After one hour, media was changed to M199 media supplemented with $100 \mathrm{units} / \mathrm{mL}$ penicillin, $100 \mu \mathrm{g} / \mathrm{mL}$ streptomycin. Cells were subjected to the respective treatments after 24h. To induce ER stress in vitro, $10 \mu \mathrm{g} / \mathrm{mL}$ tunicamycin (TM) was added to the cell media for $24 \mathrm{~h}$ in the indicated experiments. Other concentrations that were used are described in the respective figures.

\section{Method details}

\section{siRNA transfection}

Neonatal rat ventricular myocytes were plated at a density of $0.5 \times 10^{6}$ cells per well on fibronectin coated $34.8 \mathrm{~mm}$ plates and cultured in Dulbecco's modified Eagle's medium (DMEM)/F12 1:1 (cat\# 11330-032, Thermo Fisher Scientific), containing 10\% fetal bovine serum, 100 units $/ \mathrm{mL}$ of penicillin, $100 \mu \mathrm{g} / \mathrm{mL}$ streptomycin and $292 \mu \mathrm{g} / \mathrm{mL}$ glutamine for $24 \mathrm{~h}$. One day after, media was changed to DMEM/F12 $1: 1$ containing $0.5 \%$ fetal bovine serum, $120 \mathrm{nM}$ of siRNA and $0.625 \%$ HiPerFect (cat\# 301704, QIAGEN) and no antibiotics. HiPerFect transfection reagent was used to transfect cells with small interfering (si) RNA oligoribonucleotides targeted to rat ATF6 (assay ID\# RSS315363, Stealth siRNA, Thermo Fisher). A non-targeting sequence (cat\# 12935300, Thermo Fisher) was used as a control siRNA. NRVCM were incubated with the siRNA for 16 hours. Then, medium was changed to DMEM/F12 1:1 supplemented with BSA (1 mg/mL), 100 units $/ \mathrm{mL}$ of penicillin, $100 \mu \mathrm{g} / \mathrm{mL}$ streptomycin and $292 \mu \mathrm{g} / \mathrm{mL}$ glutamine. Respective treatments were initiated after 48 hours. 


\section{Adenovirus generation and transfection}

Plasmid vector construction and recombinant adenovirus generation encoding AAV9-control, AAV93XFLAG-tagged constitutively active ATF6, ATF6a(1-373), and dominant-negative ATF6a (dnATF6) has been described previously (Jin et al., 2017; Thuerauf et al., 2001; Wang et al., 2000). Transduction was performed by incubating cultures overnight with the appropriate adenovirus at a multiplicity of infection (MOI, number infectious particles per cell) of five. On the next day media was changed to DMEM/F12 1:1 supplemented with BSA ( $1 \mathrm{mg} / \mathrm{mL}), 100$ units $/ \mathrm{mL}$ of penicillin, $100 \mu \mathrm{g} / \mathrm{mL}$ streptomycin and $292 \mu \mathrm{g} / \mathrm{mL}$ glutamine. After $24 \mathrm{~h}$, desired treatments were initiated.

\section{Cultured cell area}

Phase-contrast microscopy pictures were taken from five different fields per culture ( $n=3$ individual cell cultures for each treatment). Cell area for at least 500 cells per condition was determined using FIJI (Rueden et al., 2017; Schindelin et al., 2012). The number of measured cells can be found in the respective figure legends. For cultured myocytes cell area, myocytes were seeded at a density of 0.5 $X 10^{6}$ cells per well on fibronectin coated $34.8 \mathrm{~mm}$ plates maintained in Dulbecco's modified Eagle's medium (DMEM)/F12 1:1, containing $10 \%$ fetal bovine serum, 100 units $/ \mathrm{mL}$ of penicillin, $100 \mu \mathrm{g} / \mathrm{mL}$ streptomycin and $292 \mu \mathrm{g} / \mathrm{mL}$ glutamine for $24 \mathrm{~h}$. After $24 \mathrm{~h}$ media was changed to DMEM/F12 1:1 supplemented with BSA (1 mg/mL), 100 units $/ \mathrm{mL}$ of penicillin, $100 \mu \mathrm{g} / \mathrm{mL}$ streptomycin and $292 \mu \mathrm{g} / \mathrm{ml}$

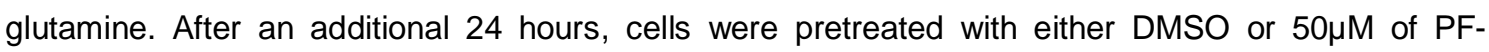
429242 dihydrochloride (cat\# SML0667, Sigma-Aldrich), diluted in DMSO, for 30 minutes and then treated with Dulbecco's phosphate buffered saline (PBS) (cat\# 14190-144, Thermo Fisher Scientific), (R)-(-)-phenylephrine hydrochloride $(50 \mu \mathrm{M})$ (cat\# P6126, Sigma-Aldrich) or isoproterenol $(10 \mu \mathrm{M})$ diluted in PBS, for 24h. For siRNA and adenovirus transfection cells were treated as described above.

\section{Immunofluorescence}

Cardiac myocytes were isolated as described above. Cardiac myocytes were then plated on glass chamber slides that had been pre-treated with $25 \mu \mathrm{g} / \mathrm{mL}$ fibronectin for one hour. After the respective treatments, the slides were washed twice in PBS and then fixed with 4\% PFA for 20 minutes. Slides were washed three times for 5-10 minutes in PBS and then incubated for 10 minutes in permeabilization buffer consisting of PBS, $0.2 \%$ Triton $\mathrm{X}-100$ and $0.1 \mathrm{M}$ glycine. Then slides were washed once with PBS and then incubated with blocking buffer containing $10 \%$ horse serum and $0.2 \%$ 
Triton X-100 in PBS for one hour. Next, slides were incubated overnight at $4^{\circ} \mathrm{C}$ with primary antibody diluted in blocking buffer. The primary antibody used was anti-a-actinin (sarcomeric) (cat\# A7811, Sigma-Aldrich; 1:100). On the next day slides were washed three times for 5-10 minutes in PBS and then incubated with secondary antibody in blocking buffer for one hour. The secondary antibody used was fluorescein (FITC)-conjugated AffiniPure donkey anti-mouse IgG (cat\# 715-095-151, Jackson Immuno Research; 1:100). The slides were then washed three times for 5-10 minutes in PBS and incubated in a 1:500 solution of 1mM TO-PRO-3 iodide (cat\# T3605, Thermo Fisher Scientific) diluted in PBS for 10 minutes. Then slides were washed twice in PBS for 10 minutes and covered with VECTASHIELD Antifade Mounting Medium (cat\# H-1000, Vector Laboratories) and a glass plate and visualized by microscopy. Immunocytofluorescence of mouse heart sections was performed as previously reported (Doroudgar et al., 2015). Primary antibodies used were anti-tropomyosin (cat\# T9283, Sigma-Aldrich; 1:200) and anti-A11 (1:200). For detection of A11, a biotinylated goat anti-rabbit (Vector Laboratories, BA-1000) secondary was required. Secondary antibodies used were Alexa Fluo 488. Images were obtained using a Leica DMi8 confocal laser scanning microscope.

\section{Cell viability}

For quantification of viability cells were subjected to the respective treatments. Then, $1 \mu \mathrm{g} / \mathrm{mL}$ of propidium iodide (cat\# P21493, Thermo Fisher Scientific) and $5 \mu \mathrm{g} / \mathrm{mL}$ of Hoechst 33342, trihydrochloride, trihydrate (cat\# H21492, Thermo Fisher Scientific) was added to the culture media. After 10 minutes fluorescent images of random positions of the cell culture area were taken using a ZEISS Axio Vert.A1 microscope. Propidium iodide positive and negative cells were quantified with FIJI (Schindelin et al., 2012).

\section{Isoprenaline model of cardiac hypertrophy}

Male WT and ATF6 KO mice at 10 weeks of age were randomly assigned to the experimental groups. To induce cardiac hypertrophy, mice were subjected to either Lactated Ringer's solution or 30mg/kg/day Isoprenaline (cat\# 16504, Sigma-Aldrich) treatment via ALZET mini-osmotic pump implants (Model 1007D, cat\# 0000290) for seven days. For osmotic pump implantation, mice were anesthetized with isoflurane. Pumps were inserted subcutaneously through a small incision at the 
lower back. Mice received daily intraperitoneal injections of $1 \mu \mathrm{l} / \mathrm{g}$ of $0.1 \mathrm{mg} / \mathrm{mL}$ buprenorphine solution, diluted in phosphate-buffered saline at time of surgery and up to $2 \mathrm{~d}$ after surgery.

\section{TAC surgery}

Animals were randomly assigned to the experimental groups. TAC was performed as previously described (Blackwood et al., 2019a). Briefly, adult male mice were anesthetized using a 2\% isofluorane/O2 mixture and intubated. Mice were treated with buprenorphine $(0.1 \mathrm{mg} / \mathrm{kg} \mathrm{IP})$ and a partial trans-sternal thoracotomy performed using aseptic technique. An approximately $1.5 \mathrm{~cm}$ vertical left parasternal skin incision was made, underlying pectoralis muscle retracted, and the chest cavity entered through the fourth intercostal space. Using hooked retractors, adjacent ribs were retracted to expose the heart and aortic arch. The aorta was isolated from annexed tissue, and the artery partially ligated between the innominate and left common carotid arteries with 6-0 silk. The calibrated constriction of the aorta was performed by placing a dull 27- gauge needle to the side of the artery, the ligature tied firmly to both the needle and the artery, and, subsequently, the needle was removed leaving a calibrated stenosis of the aorta. Sham operated mice were exposed to the same procedure, except that the aorta was not constricted. The thoracic cavity was closed and the animals were allowed to recover. Animals were injected once with buprenorphine $(0.1 \mathrm{mg} / \mathrm{kg} \mathrm{IP})$ about $12 \mathrm{~h}$ after recovery in order to reduce any post-operative discomfort. In case any animals displayed signs of pain or distress after this period, additional doses of buprenorphine were administered as needed. Shamoperated mice were euthanized at time points matching to TAC surgery time points.

\section{Echocardiography}

Echocardiography was carried out on anesthetized mice using a Visualsonics Vevo 2100 highresolution echocardiograph (Tsujita et al., 2005). Anesthesia was administered via a facial mask and maintained by a minimum dose of isoflurane (1.0-2.0\%). Echocardiography was performed at a heart rate of $450-550 \mathrm{bpm}$.

\section{Preparation of tissue lysates}

Mice were sacrificed and different tissues were rapidly excised, washed in PBS and snap frozen in liquid nitrogen. Different tissues were homogenized using a tissue homogenizer in 5 volumes of ice- 
cold polysome buffer containing $20 \mathrm{mM}$ Tris $\mathrm{pH} 7.4,10 \mathrm{mM} \mathrm{MgCl}, 200 \mathrm{mM} \mathrm{KCl}$ and $1 \%$ Trition X-100. For protein analysis via immunoblotting, initial lysates were further diluted with 9 volumes of RIPA buffer containing $20 \mathrm{mM}$ Tris- $\mathrm{HCl}(\mathrm{pH} 7.4), 150 \mathrm{mM} \mathrm{NaCl}, 1 \%$ Triton $\mathrm{X}-100,0.1 \%$ SDS, $0,5 \%$ Sodium deoxycholate, protease inhibitor cOmplete ULTRA (cat\# 05892791001, Roche) and phosphatase inhibitor PhosSTOP (cat\# 04906837001, Sigma-Aldrich). RNA was isolated from tissue lysates using the RNeasy Mini Kit (cat\# 74104, Qiagen).

\section{Immunoblotting}

Cultured cells and mouse tissues were lysed in RIPA Buffer consisting of $50 \mathrm{mM}$ Tris pH 7.5, 150mM $\mathrm{NaCl}, 1 \%$ Triton $\mathrm{X}-100$ and $1 \%$ SDS, which was supplemented with protease inhibitor cOmplete ULTRA (cat\# 05892791001, Roche) phosphatase inhibitor PhosSTOP (cat\# 04906837001, Roche). Lysates were cleared by centrifugation at $4{ }^{\circ} \mathrm{C}$ for 10 minutes at 20.000 rcf. Lysate protein concentration was determined using DC Protein Assay Kit II (cat\# 5000112, Bio-Rad). Equivalent amounts of protein, usually $20-30 \mu \mathrm{g}$, were brought up to similar volume, mixed with Laemmli Sample Buffer (Bio-Rad; 161-0747) and 2-Mercapoethanol (cat\# M6250, Sigma-Aldrich) and boiled at $95^{\circ} \mathrm{C}$ for 5 minutes. Samples were separated on SDS-PAGE gels and transferred to Immobilon-P transfer membranes (cat\# IPVH00010, Merck Millipore). The following antibodies were used to probe the membranes: GAPDH (cat\# G-9, sc-365062, Santa Cruz Biotechnology; 1:20,000), $\beta$-Actin (cat\# C4, sc-47778, Santa Cruz Biotechnology; 1:20,000), KDEL (cat\# 10C3, ADI-SPA-827, ENZO Life Sciences; 1:2,000-5,000), ATF6 (cat\# 24169-1-AP, Proteintech; 1:1,000), Puromycin (cat\# MABE343, Merck Millipore; 1:2,000-1:10,000), anti-Ubiquitinylated proteins,clone FK2 (cat\# 04-263, Merck Millipore; 1:1000). Ponceau solution was prepared with Ponceau BS (cat\# B6008, Sigma Aldrich).

\section{Quantitative Real Time PCR}

Total RNA was isolated from cultured cardiomyocytes using the Quick-RNA MiniPrep Kit (cat\# R1055, Zymo Research) and from tissue using the RNeasy Mini Kit (cat\# 74104, Qiagen). cDNA was generated by reverse transcription using Superscript III First-Strand Synthesis System (Invitrogen; 18080-051). Quantitative Real Time PCR was performed with Maxima SYBR Green/ROX qPCR Master Mix (Thermo Fisher cat\# K0222) in a StepOnePlus RT-PCR System (Thermo Fisher). 


\section{Xbp1 splicing}

XBP1 splicing was assessed with Real Time PCR using the following primers: FW ACGAGAGAAAACTCATGGGC; Rev ACAGGGTCCAACTTGTCCAG. CDNA was run on a $2 \%$ agarose gel at $130 \mathrm{~V}$ for one hour and viewed by UV illumination.

\section{Sequencing data analysis}

Transcript profiling of ATF6 KO mice was performed as previously described. Briefly, total RNA was isolated from mouse left ventricular extracts and RNA sequencing was carried out on Illumina Nextseq at CellNetworks Deep Sequencing Core Facility at Heidelberg University. Sequencing adapter residues and low-quality bases were removed from raw sequencing reads prior to all other analysis steps using Flexbar version 3.0.315 (Roehr et al., 2017). Subsequently, reads mapping to known ribosomal RNA species were excluded from further analyses using Bowtie2 version 2.3.0 (Langmead and Salzberg, 2012) with a custom rRNA index and only keeping non-aligning reads. Principal read mapping against the mouse reference genome (GRCm39, Ensembl release 102) was performed with the STAR aligner, version 2.5.3a17 (Dobin et al., 2013). The read-to-transcript assignment was carried out using the R package Rsubread version 1.24.218 (Liao et al., 2019) and the ENSMBL gene annotation GRCm39, Ensembl release 102. The resulting count table was further processed with the edgeR R package19 (Robinson et al., 2010) to construct the list of differentially expressed genes. RNA-Seq, ribosome profiling and proteomics gene expression data of TAC $3 \mathrm{~h}, 2 \mathrm{~d}$, and $2 \mathrm{wk}$ relative to time-matched Sham mice was obtained from our previously published dataset (Doroudgar et al., 2019). Significantly regulated genes were defined as FDR $<0.05$. ATF6 and XBP1s target genes were identified from Shoulders et al. (2013). Due to incorrectly reported q-values in the available gene list from Shoulders et al. (2013) (Shoulders et al., 2013), novel q-values were derived from the reversed log10 scores of Benjamini-Hochberg. PERK-selective target genes were identified from Lu et al. (Lu et al., 2004). PERK-selective target genes were defined as genes induced both $>2$ fold in AP20187 treated elF2a (S/S) Fv2E-PERK cells at $8 \mathrm{~h}$ and $>2$ fold in TM treated WT cells at 6 hours. 'Unfolded protein response genes' were defined as the merged gene entries from the GO categories GO:0006986 (response to unfolded protein), GO:0030968 (endoplasmic reticulum unfolded protein response) and GO:0034976 (response to endoplasmic reticulum stress).

\section{Gene Ontology analysis}

GO term enrichment analysis was performed as previously described. Briefly, genes with FDR $<0.05$ 
were considered for further analysis. GOTERM_BP_DIRECT in DAVID v6.8 (Dennis et al., 2003; Huang et al., 2009) was used with the subset of expressed protein-coding genes as background set. Only enriched GO terms with at least five significantly changed genes were kept for further analysis and ranked by $\mathrm{p}$-value. Top enriched terms were retained and visualized with a custom plotting routine showing enrichment p-value.

\section{Quantification and statistical analysis}

Statistical analysis was performed using GraphPad Prism 7.0 (Graphpad Software Inc; www.graphpad.com) or R (R Foundation; https://www.r-project.org). Data values are mean \pm standard error of the mean (SEM). For statistical analysis one-way ANOVA with Turkey post-hoc analysis or when only two conditions where compared, unpaired two tailed t-test was used. $p<0.05$ was defined as significant difference. Details of the statistical analyses of the sequencing data can be found in the method details. Biological replicate numbers for each figure can be found in the accompanying figure legend. 


\section{Acknowledgments}

This work was supported by grants from the German Centre for Cardiovascular Research (DZHK), the University of Arizona College of Medicine - Phoenix, and the Translational Cardiovascular Research Center at the University of Arizona College of Medicine - Phoenix to S.D. C.H. acknowledges support by a Boehringer Ingelheim Fonds Travel Grant, the DZHK mobility program, and the German Heart Foundation (Deutsche Herzstiftung). R.J.K. acknowledges support from National Institutes of Health (NIH) grant R01 AG062190. C.C.G. acknowledges NIH grants 1HL135893, 1HL141463, and $1 \mathrm{HL} 149931$. E.A.B acknowledges $\mathrm{NIH}$ grant $1 \mathrm{~F} 31 \mathrm{HL} 140850$, the Inamori Foundation, the

Achievement Rewards for College Scientists Foundation, Inc, San Diego Chapter, the Rees-Stealy Research Foundation Phillips Gausewitz, MD, Scholarship of the San Diego State University Heart Institute.

\section{Author contributions}

Conceptualization, C.C.G., C.H. and S.D.; Methodology, C.H., C.S., E.A.B., J.G., M.V., N.H., S.D. and T.J.; Investigation C.H., C.S., E.A.B., J.G. and N.H.; Formal Analysis C.H. and T.J.; Visualization C.H. and S.D.; Providing critical reagents and advice R.J.K; Writing - Original Draft C.H. and S.D.; Writing Review \& Editing C.H. and S.D. with input from all authors; Resources C.C.G., H.A.K, M.V. and S.D.; Supervision C.C.G., M.V., S.D.; Funding Acquisition C.C.G., H.A.K., M.V. and S.D.; Project Administration S.D.

\section{Declaration of interest}

The authors declare no conflict of interest. 


\section{References}

Aguilaniu, H., Gustafsson, L., Rigoulet, M. and Nyström, T. (2003). Asymmetric Inheritance of Oxidatively Damaged Proteins During Cytokinesis. Science (80-. ). 299, 1751 LP - 1753.

Ayyadevara, S., Mercanti, F., Wang, X., Mackintosh Samuel, G., Tackett Alan, J., Prayaga Sastry, V. S., Romeo, F., Shmookler Reis Robert, J. and Mehta Jawahar, L. (2016). Age- and HypertensionAssociated Protein Aggregates in Mouse Heart Have Similar Proteomic Profiles. Hypertension 67, 1006-1013.

Ben-Zvi, A., Miller, E. A. and Morimoto, R. I. (2009). Collapse of proteostasis represents an early molecular event in Caenorhabditis elegans aging. Proc. Natl. Acad. Sci. U. S. A. 106, 1491414919.

Bhuiyan, M. S., Pattison, J. S., Osinska, H., James, J., Gulick, J., McLendon, P. M., Hill, J. A., Sadoshima, J. and Robbins, J. (2013). Enhanced autophagy ameliorates cardiac proteinopathy. J. Clin. Invest. 123, 5284-5297.

Blackwood, E. A., Hofmann, C., Santo Domingo, M., Bilal, A. S., Sarakki, A., Stauffer, W., Arrieta, A., Thuerauf, D. J., Kolkhorst, F. W., Müller, O. J., et al. (2019a). ATF6 Regulates Cardiac Hypertrophy by Transcriptional Induction of the mTORC1 Activator, Rheb. Circ. Res. 124, 79-93.

Blackwood, E. A., Azizi, K., Thuerauf, D. J., Paxman, R. J., Plate, L., Kelly, J. W., Wiseman, R. L. and Glembotski, C. C. (2019b). Pharmacologic ATF6 activation confers global protection in widespread disease models by reprograming cellular proteostasis. Nat. Commun. 10, 187.

Burkewitz, K., Feng, G., Dutta, S., Kelley, C. A., Steinbaugh, M., Cram, E. J. and Mair, W. B. (2020). Atf-6 Regulates Lifespan through ER-Mitochondrial Calcium Homeostasis. Cell Rep. 32, 108125.

Cardoso-Moreira, M., Halbert, J., Valloton, D., Velten, B., Chen, C., Shao, Y., Liechti, A., Ascenção, K., Rummel, C., Ovchinnikova, S., et al. (2019). Gene expression across mammalian organ development. Nature 571, 505-509.

Chen, D., Thomas, E. L. and Kapahi, P. (2009). HIF-1 Modulates Dietary Restriction-Mediated Lifespan Extension via IRE-1 in Caenorhabditis elegans. PLOS Genet. 5, e1000486.

Correll, R. N., Grimes, K. M., Prasad, V., Lynch, J. M., Khalil, H. and Molkentin, J. D. (2019). Overlapping and differential functions of ATF6 $\alpha$ versus ATF6 in the mouse heart. Sci. Rep. 9, 2059.

Cox, J. S., Shamu, C. E. and Walter, P. (1993). Transcriptional induction of genes encoding endoplasmic reticulum resident proteins requires a transmembrane protein kinase. Cell 73, 1197-1206. 
David, D. C., Ollikainen, N., Trinidad, J. C., Cary, M. P., Burlingame, A. L. and Kenyon, C. (2010). Widespread protein aggregation as an inherent part of aging in C. elegans. PLOS Biol. 8, e1000450-e1000450.

Dennis, G., Sherman, B. T., Hosack, D. A., Yang, J., Gao, W., Lane, H. C. and Lempicki, R. A. (2003). DAVID: Database for Annotation, Visualization, and Integrated Discovery. Genome Biol. 4, R60.

Dobin, A., Davis, C. A., Schlesinger, F., Drenkow, J., Zaleski, C., Jha, S., Batut, P., Chaisson, M. and Gingeras, T. R. (2013). STAR: ultrafast universal RNA-seq aligner. Bioinformatics 29, 15-21.

Doroudgar, S., Thuerauf, D. J. D. J., Marcinko, M. C. M. C., Belmont, P. J. P. J. and Glembotski, C. C. C. (2009). Ischemia Activates the ATF6 Branch of the Endoplasmic Reticulum Stress Response *. J. Biol. Chem. 284,.

Doroudgar, S., Völkers, M., Thuerauf, D. J., Khan, M., Mohsin, S., Respress, J. L., Wang, W., Gude, N. A., Müller, O. J., Wehrens, X. H. T., et al. (2015). Hrd1 and ER-Associated Protein Degradation, ERAD, Are Critical Elements of the Adaptive ER Stress Response in Cardiac Myocytes. Circ. Res. $117,536-546$.

Doroudgar, S., Hofmann, C., Boileau, E., Malone, B., Riechert, E., Gorska Agnieszka, A., Jakobi, T., Sandmann, C., Jürgensen, L., Kmietczyk, V., et al. (2019). Monitoring Cell-Type-Specific Gene Expression Using Ribosome Profiling In Vivo During Cardiac Hemodynamic Stress. Circ. Res. 125, 431-448.

Eisenberg, T., Abdellatif, M., Schroeder, S., Primessnig, U., Stekovic, S., Pendl, T., Harger, A., Schipke, J., Zimmermann, A., Schmidt, A., et al. (2016). Cardioprotection and lifespan extension by the natural polyamine spermidine. Nat. Med. 22, 1428-1438.

Frey, N. and Olson, E. N. (2003). Cardiac hypertrophy: the good, the bad, and the ugly. Annu Rev Physiol 65, 45-79.

Glembotski, C. C. (2014). Roles for ATF6 and the sarco/endoplasmic reticulum protein quality control system in the heart. J. Mol. Cell. Cardiol. 71, 11-15.

Han, J. and Kaufman, R. J. (2017). Physiological/pathological ramifications of transcription factors in the unfolded protein response. Genes Dev. 31, 1417-1438.

Harding, H. P., Zhang, Y. and Ron, D. (1999). Protein translation and folding are coupled by an endoplasmic- reticulum-resident kinase. Nature 397, 271-274.

Harrison, D. E., Strong, R., Sharp, Z. D., Nelson, J. F., Astle, C. M., Flurkey, K., Nadon, N. L., Wilkinson, J. E., Frenkel, K., Carter, C. S., et al. (2009). Rapamycin fed late in life extends lifespan in genetically heterogeneous mice. Nature 460, 392-395. 
Haze, K., Yoshida, H., Yanagi, H., Yura, T. and Mori, K. (1999). Mammalian transcription factor ATF6 is synthesized as a transmembrane protein and activated by proteolysis in response to endoplasmic reticulum stress. Mol. Biol. Cell 10, 3787-3799.

Henis-Korenblit, S., Zhang, P., Hansen, M., McCormick, M., Lee, S.-J., Cary, M. and Kenyon, C. (2010). Insulin/IGF-1 signaling mutants reprogram ER stress response regulators to promote longevity. Proc. Natl. Acad. Sci. 107, 9730.

Hetz, C. and Papa, F. R. (2018). The Unfolded Protein Response and Cell Fate Control. Mol. Cell 69, 169-181.

Hidalgo San Jose, L., Sunshine, M. J., Dillingham, C. H., Chua, B. A., Kruta, M., Hong, Y., Hatters, D. M. and Signer, R. A. J. (2020). Modest Declines in Proteome Quality Impair Hematopoietic Stem Cell Self-Renewal. Cell Rep. 30, 69-80.e6.

Hill, J. A. and Olson, E. N. (2008). Cardiac plasticity. N. Engl. J. Med. 358, 1370.

Hipp, M. S., Kasturi, P. and Hartl, F. U. (2019). The proteostasis network and its decline in ageing. Nat. Rev. Mol. Cell Biol. 20, 421-435.

Hofmann, C., Katus, H. A. and Doroudgar, S. (2019). Protein Misfolding in Cardiac Disease. Circulation 139, 2085-2088.

Huang, D. W., Sherman, B. T. and Lempicki, R. A. (2009). Systematic and integrative analysis of large gene lists using DAVID bioinformatics resources. Nat. Protoc. 4, 44-57.

Jin, J. K., Blackwood, E. A., Azizi, K., Thuerauf, D. J., Fahem, A. G., Hofmann, C., Kaufman, R. J., Doroudgar, S. and Glembotski, C. C. (2017). ATF6 Decreases Myocardial Ischemia/Reperfusion Damage and Links ER Stress and Oxidative Stress Signaling Pathways in the Heart. Circ. Res. 120, 862-875.

Kaushik, S. and Cuervo, A. M. (2015). Proteostasis and aging. Nat. Med. 21, 1406-1415.

Kikis, E. A., Gidalevitz, T. and Morimoto, R. I. (2010). Protein homeostasis in models of aging and age-related conformational disease. Adv. Exp. Med. Biol. 694, 138-159.

Klaips, C. L., Jayaraj, G. G. and Hartl, F. U. (2018). Pathways of cellular proteostasis in aging and disease. J. Cell Biol. 217, 51-63.

Labbadia, J. and Morimoto, R. I. (2014). Proteostasis and longevity: when does aging really begin? F1000Prime Rep. 6, 7.

Labbadia, J. and Morimoto, R. I. (2015). The Biology of Proteostasis in Aging and Disease. Annu. Rev. Biochem. 84, 435-464. 
Labunskyy, V. M., Gerashchenko, M. V, Delaney, J. R., Kaya, A., Kennedy, B. K., Kaeberlein, M. and Gladyshev, V. N. (2014). Lifespan Extension Conferred by Endoplasmic Reticulum Secretory Pathway Deficiency Requires Induction of the Unfolded Protein Response. PLOS Genet. 10, e1004019.

Langmead, B. and Salzberg, S. L. (2012). Fast gapped-read alignment with Bowtie 2. Nat. Methods 9, 357.

Liao, Y., Smyth, G. K. and Shi, W. (2019). The R package Rsubread is easier, faster, cheaper and better for alignment and quantification of RNA sequencing reads. Nucleic Acids Res. 47, e47e47.

Lu, P. D., Jousse, C., Marciniak, S. J., Zhang, Y., Novoa, I., Scheuner, D., Kaufman, R. J., Ron, D. and Harding, H. P. (2004). Cytoprotection by pre-emptive conditional phosphorylation of translation initiation factor 2. EMBO J. 23, 169-179.

Lynch, J. M., Maillet, M., Vanhoutte, D., Schloemer, A., Sargent, M. A., Blair, N. S., Lynch, K. A., Okada, T., Aronow, B. J., Osinska, H., et al. (2012). A thrombospondin-dependent pathway for a protective ER stress response. Cell 149, 1257-1268.

Martindale, J. J., Fernandez, R., Thuerauf, D., Whittaker, R., Gude, N., Sussman, M. A. and Glembotski, C. C. (2006). Endoplasmic reticulum stress gene induction and protection from ischemia/reperfusion injury in the hearts of transgenic mice with a tamoxifen-regulated form of ATF6. Circ Res 98, 1186-1193.

Matai, L., Sarkar, G. C., Chamoli, M., Malik, Y., Kumar, S. S., Rautela, U., Jana, N. R., Chakraborty, K. and Mukhopadhyay, A. (2019). Dietary restriction improves proteostasis and increases life span through endoplasmic reticulum hormesis. Proc. Natl. Acad. Sci. 116, 17383.

McLendon, P. M. and Robbins, J. (2015). Proteotoxicity and Cardiac Dysfunction. Circ. Res. 116, $1863-1882$.

Mohammed, S. F., Mirzoyev, S. A., Edwards, W. D., Dogan, A., Grogan, D. R., Dunlay, S. M., Roger, V. L., Gertz, M. A., Dispenzieri, A., Zeldenrust, S. R., et al. (2014). Left Ventricular Amyloid Deposition in Patients With Heart Failure and Preserved Ejection Fraction. JACC Hear. Fail. 2, $113-122$.

Morl, K., Ma, W., Gething, M.-J. and Sambrook, J. (1993). A transmembrane protein with a cdc2+CDC28-related kinase activity is required for signaling from the ER to the nucleus. Cell 74, $743-756$.

Okada, K., Minamino, T., Tsukamoto, Y., Liao, Y., Tsukamoto, O., Takashima, S., Hirata, A., Fujita, 
M., Nagamachi, Y., Nakatani, T., et al. (2004). Prolonged Endoplasmic Reticulum Stress in Hypertrophic and Failing Heart After Aortic Constriction. Possible Contrib. Endoplasmic Reticulum Stress to Card. Myocyte Apoptosis 110, 705-712.

Pattison, J. S., Sanbe, A., Maloyan, A., Osinska, H., Klevitsky, R. and Robbins, J. (2008).

Cardiomyocyte expression of a polyglutamine preamyloid oligomer causes heart failure. Circulation 117, 2743-2751.

Pinto, A. R., Ilinykh, A., Ivey, M. J., Kuwabara, J. T., D’antoni, M. L., Debuque, R., Chandran, A., Wang, L., Arora, K., Rosenthal, N. A., et al. (2016). Revisiting cardiac cellular composition. Circ. Res. 118, 400-409.

Rainer, P. P., Dong, P., Sorge, M., Fert-Bober, J., Holewinski, R. J., Wang, Y., Foss, C. A., An, S. S., Baracca, A., Solaini, G., et al. (2018). Desmin Phosphorylation Triggers Preamyloid Oligomers Formation and Myocyte Dysfunction in Acquired Heart Failure. Circ. Res. 122, e75-e83.

Robinson, M. D., McCarthy, D. J. and Smyth, G. K. (2010). edgeR: a Bioconductor package for differential expression analysis of digital gene expression data. Bioinformatics 26, 139-140.

Rockman, H. A., Ross, R. S., Harris, A. N., Knowlton, K. U., Steinhelper, M. E., Field, L. J., Ross, J. and Chien, K. R. (1991). Segregation of atrial-specific and inducible expression of an atrial natriuretic factor transgene in an in vivo murine model of cardiac hypertrophy. Proc. Natl. Acad. Sci. U. S. A. $88,8277-81$.

Roehr, J. T., Dieterich, C. and Reinert, K. (2017). Flexbar 3.0 - SIMD and multicore parallelization. Bioinformatics 33, 2941-2942.

Rueden, C. T., Schindelin, J., Hiner, M. C., DeZonia, B. E., Walter, A. E., Arena, E. T. and Eliceiri, K. W. (2017). ImageJ2: ImageJ for the next generation of scientific image data. BMC Bioinformatics 18,529 .

Sanbe, A., Osinska, H., Saffitz, J. E., Glabe, C. G., Kayed, R., Maloyan, A. and Robbins, J. (2004). Desmin-related cardiomyopathy in transgenic mice: A cardiac amyloidosis. Proc. Natl. Acad. Sci. U. S. A. 101, 10132 LP - 10136.

Schiattarella, G. G., Altamirano, F., Tong, D., French, K. M., Villalobos, E., Kim, S. Y., Luo, X., Jiang, N., May, H. I., Wang, Z. V, et al. (2019). Nitrosative stress drives heart failure with preserved ejection fraction. Nature 568, 351-356.

Schindelin, J., Arganda-Carreras, I., Frise, E., Kaynig, V., Longair, M., Pietzsch, T., Preibisch, S., Rueden, C., Saalfeld, S., Schmid, B., et al. (2012). Fiji: an open-source platform for biologicalimage analysis. Nat. Methods 9, 676-682. 
Sekiya, M., Maruko-Otake, A., Hearn, S., Sakakibara, Y., Fujisaki, N., Suzuki, E., Ando, K. and lijima, K. M. (2017). EDEM Function in ERAD Protects against Chronic ER Proteinopathy and AgeRelated Physiological Decline in Drosophila. Dev. Cell 41, 652-664.e5.

Shen, J., Chen, X., Hendershot, L. and Prywes, R. (2002). ER Stress Regulation of ATF6 Localization by Dissociation of BiP/GRP78 Binding and Unmasking of Golgi Localization Signals. Dev. Cell 3, 99111.

Shore, D. E., Carr, C. E. and Ruvkun, G. (2012). Induction of Cytoprotective Pathways Is Central to the Extension of Lifespan Conferred by Multiple Longevity Pathways. PLOS Genet. 8, e1002792.

Shoulders, M. D., Ryno, L. M., Genereux, J. C., Moresco, J. J., Tu, P. G., Wu, C., Yates, J. R., Su, A. I., Kelly, J. W. and Wiseman, R. L. (2013). Stress-Independent Activation of XBP1s and/or ATF6 Reveals Three Functionally Diverse ER Proteostasis Environments. Cell Rep. 3, 1279-1292.

Singh, S. R. and Robbins, J. (2018). Desmin and Cardiac Disease: An Unfolding Story. Circ. Res. 122, 1324-1326.

Takaoka, H., Esposito, G., Mao, L., Suga, H. and Rockman, H. A. (2002). Heart size-independent analysis of myocardial function in murine pressure overload hypertrophy. Am. J. Physiol. Circ. Physiol. 282, H2190-H2197.

Tannous, P., Zhu, H., Nemchenko, A., Berry, J. M., Johnstone, J. L., Shelton, J. M., Miller Jr., F. J., Rothermel, B. A. and Hill, J. A. (2008). Intracellular protein aggregation is a proximal trigger of cardiomyocyte autophagy. Circulation 117, 3070-3078.

Tardiff, J. C. (2006). Cardiac hypertrophy: stressing out the heart. J. Clin. Invest. 116, 1467-1470.

Taylor, R. C. and Dillin, A. (2013). XBP-1 is a cell-nonautonomous regulator of stress resistance and longevity. Cell 153, 1435-1447.

Thuerauf, D. J., Hoover, H., Meller, J., Hernandez, J., Su, L., Andrews, C., Dillmann, W. H., McDonough, P. M. and Glembotski, C. C. (2001). Sarco/endoplasmic Reticulum Calcium ATPase-2 Expression Is Regulated by ATF6 during the Endoplasmic Reticulum Stress Response: INTRACELLULAR SIGNALING OF CALCIUM STRESS IN A CARDIAC MYOCYTE MODEL SYSTEM. J. Biol. Chem. 276, 48309-48317.

Tsujita, Y., Kato, T. and Sussman, M. A. (2005). Evaluation of left ventricular function in cardiomyopathic mice by tissue Doppler and color M-mode Doppler echocardiography. Echocardiography 22, 245-253.

Völkers, M., Weidenhammer, C., Herzog, N., Qiu, G., Spaich, K., Wegner, F. V, Peppel, K., Müller, 0. J., Schinkel, S., Rabinowitz, J. E., et al. (2011). The inotropic peptide $\beta$ ARKct improves $\beta A R$ 
responsiveness in normal and failing cardiomyocytes through $\mathrm{G}(\beta \gamma)$-mediated L-type calcium current disinhibition. Circ. Res. 108, 27-39.

Wang, X. and Robbins, J. (2006). Heart Failure and Protein Quality Control. Circ. Res. 99, 1315-1328.

Wang, Y., Shen, J., Arenzana, N., Tirasophon, W., Kaufman, R. J. and Prywes, R. (2000). Activation of ATF6 and an ATF6 DNA Binding Site by the Endoplasmic Reticulum Stress Response*. J. Biol.

Chem. 275, 27013-27020.

Wang, X., Osinska, H., Klevitsky, R., Gerdes, A. M., Nieman, M., Lorenz, J., Hewett, T. and Robbins, J. (2001). Expression of R120G- $\alpha$ B-Crystallin Causes Aberrant Desmin and $\alpha$ B-Crystallin Aggregation and Cardiomyopathy in Mice. Circ. Res. 89, 84-91.

Wang, Y., Zhang, Y., Ding, G., May, H. I., Xu, J., Gillette, T. G., Wang, H. and Wang, Z. V (2017). Temporal dynamics of cardiac hypertrophic growth in response to pressure overload. Am. J. Physiol. Heart Circ. Physiol. 313, H1119-H1129.

Wu, J., Rutkowski, D. T., Dubois, M., Swathirajan, J., Saunders, T., Wang, J., Song, B., Yau, G. D. Y. and Kaufman, R. J. (2007). ATF6 $\alpha$ Optimizes Long-Term Endoplasmic Reticulum Function to Protect Cells from Chronic Stress. Dev. Cell 13, 351-364.

Yamamoto, K., Yoshida, H., Kokame, K., Kaufman, R. J. and Mori, K. (2004). Differential Contributions of ATF6 and XBP1 to the Activation of Endoplasmic Reticulum Stress-Responsive cis-Acting Elements ERSE, UPRE and ERSE-II. J. Biochem. 136, 343-350.

Yamamoto, K., Sato, T., Matsui, T., Sato, M., Okada, T., Yoshida, H., Harada, A. and Mori, K. (2007). Transcriptional induction of mammalian ER quality control proteins is mediated by single or combined action of ATF6alpha and XBP1. Dev. Cell 13, 365-376.

Yao, Y., Lu, Q., Hu, Z., Yu, Y., Chen, Q. and Wang, Q. K. (2017). A non-canonical pathway regulates ER stress signaling and blocks ER stress-induced apoptosis and heart failure. Nat. Commun. 8, 133. 


\section{Figure legends}

Figure 1. Extensive downregulation of protein synthesis and the UPR in tissues with low mitotic activity during mammalian adulthood.

Immunoblots of puromycin and respective quantifications for the low-mitotic tissues heart (A), skeletal muscle (B), brain (C) and the mitotic tissues kidney (D) and liver (E). Immunoblots of the UPR gene products GRP94, GRP78, and PDIA6 for the low-mitotic tissues heart (F), skeletal muscle (G), brain $(\mathrm{H})$ and the mitotic tissues kidney $(\mathrm{I})$ and liver $(\mathrm{J})$. (K) Scatter plot showing the correlation between puromycin incorporation and the mean of the normalized expression of GRP94, GRP78, and PDIA6. Colors for each organ are shown on the right. $r$ was calculated with GraphPad Prism v7.0. * indicates $p<0.05$ from neonate; \# indicates $p<0.05$ from adult.

Figure 2. Impaired expression and responsiveness of the UPR in the adult heart.

(A) Normalized RPKM values of the respective genes for human RNA sequencing data of the indicated age groups; newborn $n=2$, infant $n=3$, toddler $n=2$, teenager $n=1$, young adult $n=1$, older mid-aged $n=1$. (B) Immunoblots and quantifications for ATF6, GRP94, GRP78, and PDIA6 of neonatal and adult rat primary cardiac myocytes treated with vehicle (DMSO; control) or TM for $24 \mathrm{~h}$. (C) Relative viability of neonatal and adult rat cardiac myocytes after $24 \mathrm{~h}$ of $20 \mu \mathrm{g} / \mathrm{mL}$ TM treatment. Values are normalized to the viability of vehicle (DMSO) treated cells of the same experiment. Each dot represents the viability of all cells in a random 10x magnified cell culture view. Data are representative of three independent experiments. ${ }^{*}$ indicates $p<0.05$ from neonate. (D-F) Normalized RPKM values of the target genes of ATF6, PERK, and XBP1 pathways in human RNA sequencing data of the indicated age groups. * indicates $p<0.05$ of mean RPKM from newborn.

Figure 3. ATF6 protects from ER stress-induced cell death in cardiac myocytes but has only minor impact on cardiac UPR in the absence of stress.

(A) ATF6 PCR of WT and ATF6 KO mice showing the successful knock-out of ATF6. (B) Enrichment of gene ontology terms (biological process) of significantly changed genes. (C) Volcano plot of transcriptional changes measured by RNA sequencing in adult ATF6 KO mice compared to WT mice. The highlighted colors indicate ATF6 (red), XBP1s (blue), or PERK (yellow) target genes. The horizontal dotted line indicates an FDR of 0.05 . Genes above the line are considered significant (FDR $<0.05$ ). 4 WT and 3 ATF6 KO mice were used for the analysis. (D) Heat map showing the regulation of all ATF6 (red), XBP1s (blue) or PERK (yellow) target genes in ATF6 KO mice.

\section{Figure 4. Induction of the UPR during early adult cardiac hypertrophy.}

(A-C) Enrichment of gene ontology terms (biological process) of RNA-Seq, ribosome profiling, and quantitative mass spectrometry-based proteomics $2 d$ post-TAC or sham surgery. RNA-Seq and ribosome profiling libraries were derived from left ventricular lysates of Ribo-Tag mice, proteome data is based on isolated cardiac myocytes from similarly treated mice. ( $D$ and $E$ ) Transcriptional or translational regulation of UPR genes $2 \mathrm{~d}$ after TAC surgery. Transcripts were considered significant when false discovery rate (FDR) was $<0.05$. (F) Cell surface area measurements of adult cardiac 
myocytes in response to PBS (Veh), phenylephrine (PE), or isoproterenol (ISO) for $24 \mathrm{~h}$. At least 400 cells were counted in total per condition in three independent experiments. (G) p90 ATF6 immunoblots and respective quantification of adult cardiac myocytes after $24 \mathrm{~h}$ vehicle, PE, ISO, or TM treatment. The two visible bands of p90 ATF6 represent its glycosylated and non-glycosylated form after treatment with the glycosylation inhibitor TM. (H) mRNA levels of GRP78 (Hspa5) or GRP94 (Hsp90b1) after 24h treatment of adult cardiac myocytes with increasing PE or ISO dosages normalized to 18S mRNA. (I and J) Immunoblots and respective quantifications of GRP94, GRP78, and PDIA6 in adult cardiac myocytes treated with increasing dosages of Veh, PE, or ISO for 24h, normalized to $\beta$-actin protein levels. (K) Representative puromycin immunoblot of left ventricular lysates of sham and $2 \mathrm{~d}$ TAC treated mice with quantifications of mice after $3 \mathrm{~h}$ and $2 \mathrm{~d}$ TAC normalized to their respective sham control. (L) Polysome profiles of 10 weeks old mouse left ventricular lysates $2 \mathrm{~d}$ after sham or TAC surgery. (M) Immunoblots and respective quantification of GRP94, GRP78, and PDIA6 of left ventricular lysates from mice $3 \mathrm{~h}$ or $2 \mathrm{~d}$ after TAC surgery. Sham mice were sacrificed after $2 \mathrm{~d}$. * indicates $\mathrm{p}<0.05$ from control.

\section{Figure 5. ATF6 insufficiency impairs cardiac hypertrophy in response to stress.}

(A) ATF6 mRNA levels after siRNA mediated knock-down in neonatal cardiac myocytes. (B) Cell surface area measurements of neonatal cardiac myocytes after siRNA-mediated ATF6 knock-down in response to $\mathrm{PE}$ for 24h. ( $\mathrm{C}$ and $\mathrm{E}$ ) Heart weight (HW) to body weight (BW) ratio of WT and ATF6 KO mice subjected to sham or ISO pump implantation, or sham or TAC surgeries. (D and F) Ejection fraction of WT and ATF6 KO mice subjected to sham or ISO pump implantation, or sham or TAC surgeries. $(G)$ and $(H)$ mRNA levels of respective maladaptive remodeling genes normalized to $\beta$-Actin of mice subjected to sham or ISO pump implantation, or sham or TAC surgeries. (I) Cell surface area measurements of neonatal cardiac myocytes after dnATF6 treatment in response to PE for $24 \mathrm{~h}$. $(\mathrm{J})$ Cell surface area measurements and representative immunofluorescence images $(K)$ of neonatal cardiac myocytes after PF-429242 treatment in response to PE for 24h. At least 400 cells were counted in total per condition in three independent experiments for (B), (I) and $(J)$. Samples for $(C-H)$ were collected seven days after treatment. * indicates $p<0.05$ from control; \# indicates $p<0.05$ from control + PE (B, I and J), from WT Iso (C) or from WT TAC (D and H).

Figure 6. ATF6 deficiency blunts UPR induction in the acute phase of cardiac hypertrophy and leads to myocardial accumulation of misfolded proteins.

(A) p90 and p50 ATF6 immunoblots of WT and ATF6 KO mice subjected to sham and TAC surgeries. ( $B$ and $C$ ) mRNA levels of respective UPR genes normalized to $\beta$-Actin of WT and ATF6 KO mice subjected to sham or ISO pump implantation, or sham or TAC surgeries. (D) Ubiquitylated protein immunoblot and respective quantification of WT and ATF6 KO mice subjected to sham and TAC surgeries. (E) A11 immunoflourescence images and respective quantification of left ventricular sections from WT and ATF6 KO mice subjected to sham or TAC surgeries. Sections were co-stained with tropomyosin marking cardiac myocytes and TOPRO-3. Samples for (A - E) were collected seven days after treatment. ${ }^{*}$ indicates $\mathrm{p}<0.05$ from all other conditions; \# indicates $\mathrm{p}<0.05$ from control. 


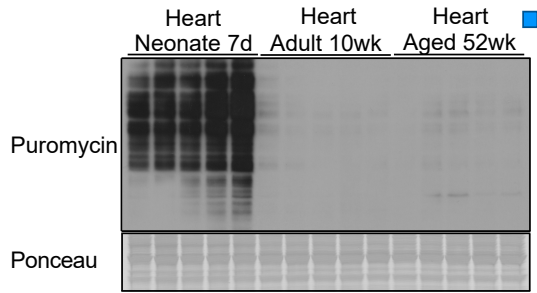

B

물

Puromycin

Muscle Muscle Muscle Neonate 7d Adult 10wk Aged 52wk

C

Ponceau

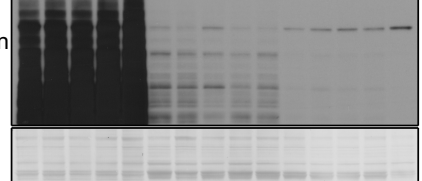

Brain Brain Brain Neonate 7d Adult 10wk Aged 52wk

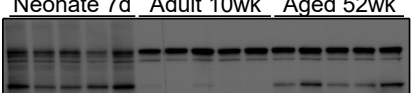

Puromycin

Kidney

Kidney

Kidney

Neonate 7d Adult 10wk Aged 52wk

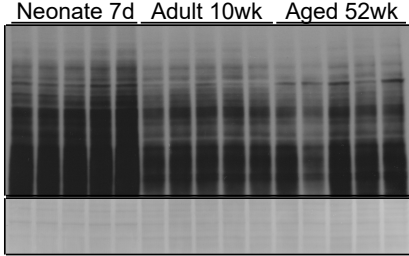

Liver Liver Liver Neonate 7d Adult 10wk Aged 52wk

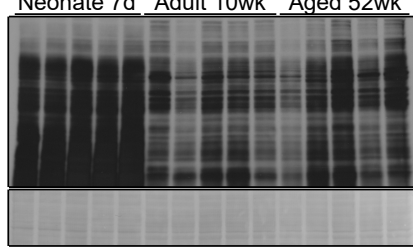

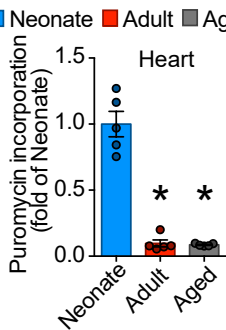
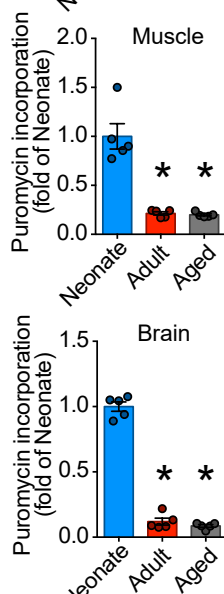

$\mathrm{H}$

GRP94

GRP78

PDIA6

Ponceau

\section{G}

GRP78

PDIA6

Ponceau

$---\frac{-1-1}{-1-1}$
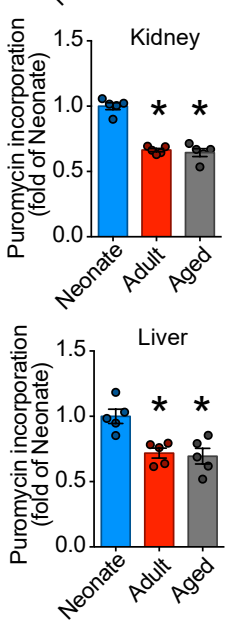

$\mathrm{H}$

Neonate

Neonate $7 \mathrm{~d}$

A Adult 10wk

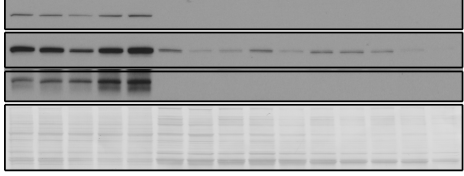

$$
\text { - }
$$

Brain
Brain
Adult 10wate 7d

Brain
Adult 10wk

Brain
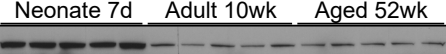

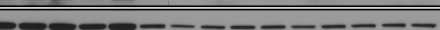
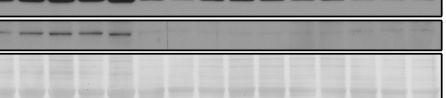

$\square$ Neonate $\square$ Adult $\square$ Aged

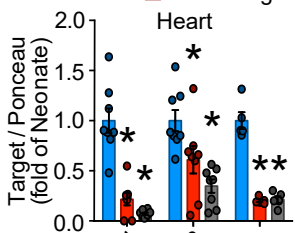

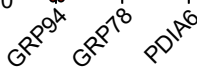
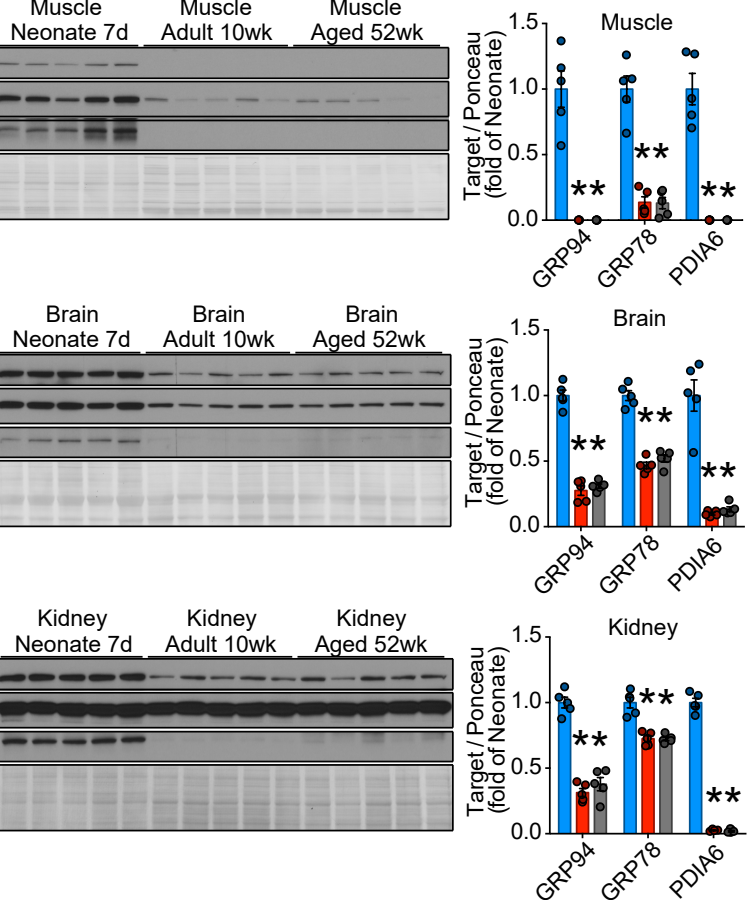

$J$

Liver
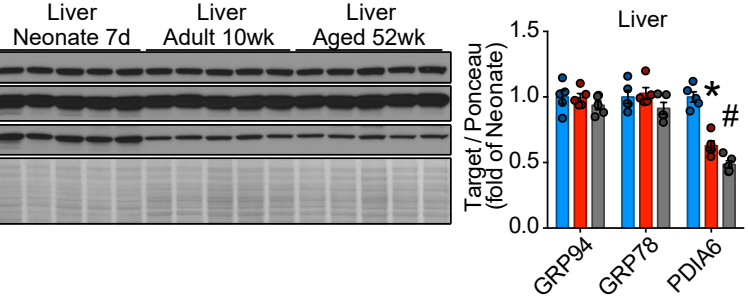
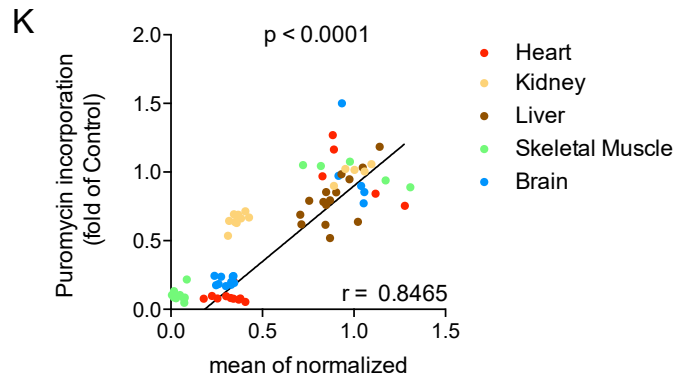

GRP94 / GRP78 / PDIA6 expression

(fold of Control) 
A

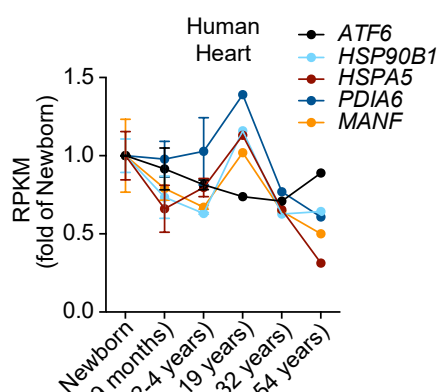

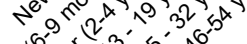

is

D Human Heart

ATF6 target genes

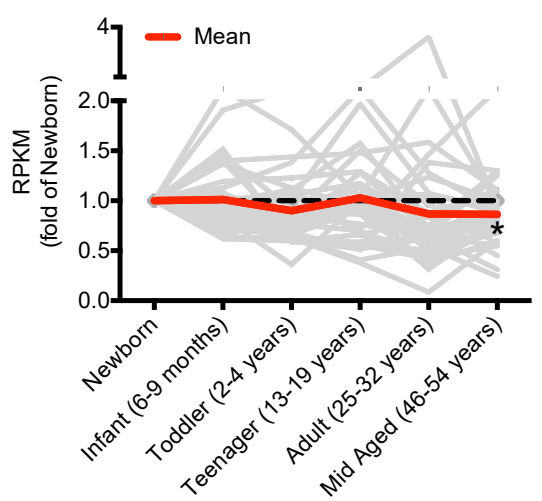

C Rat Primary Cardiac Myocytes

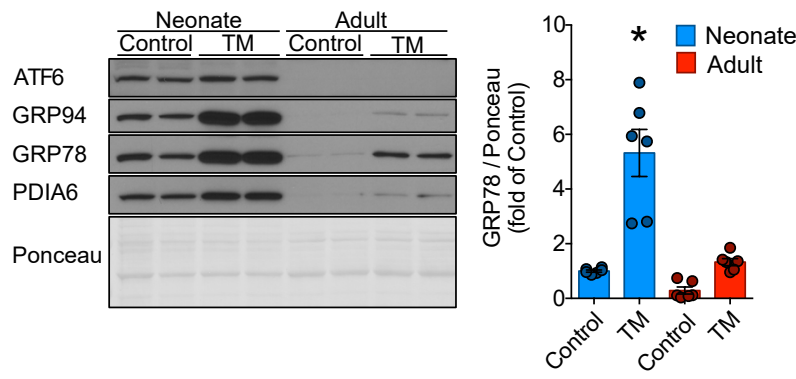

E

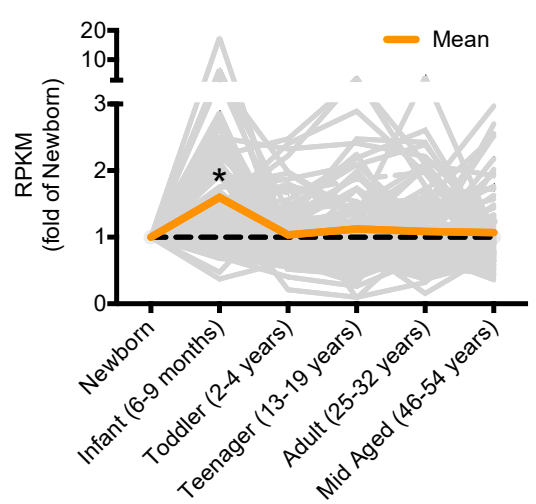

F

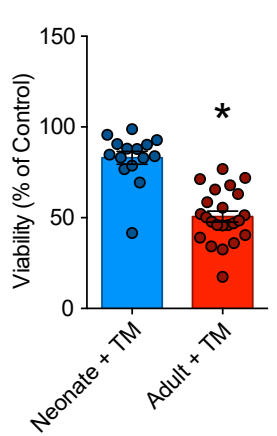

Human Heart
Human Heart PERK target genes XBP1s target genes

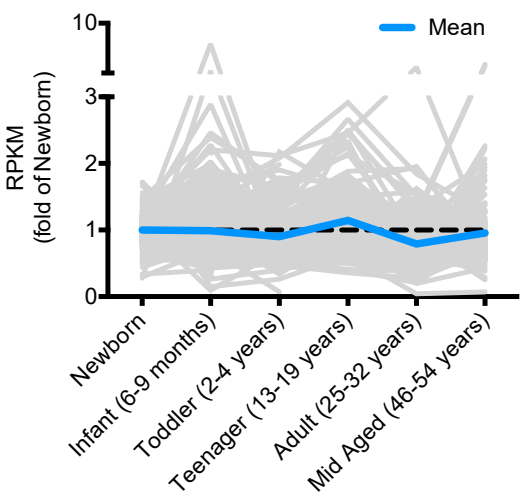


A

B

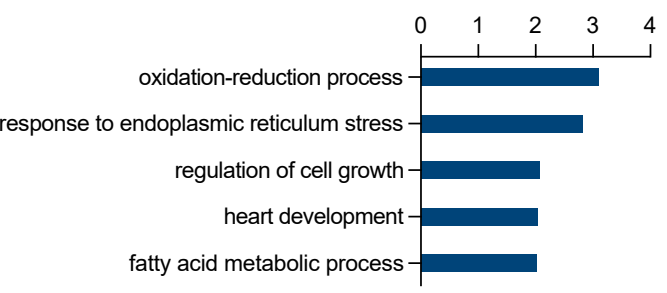

\section{C}

IFI208 . $\cdot$ CD207 $\cdot$ HAMP10

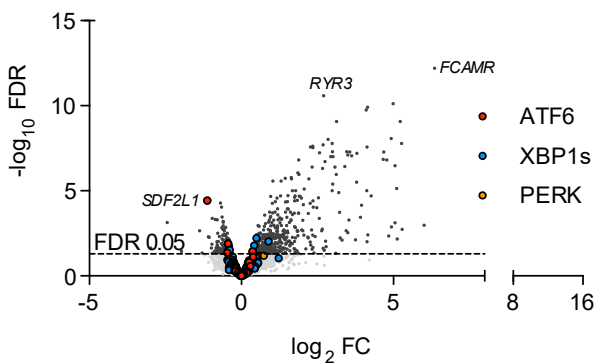

D

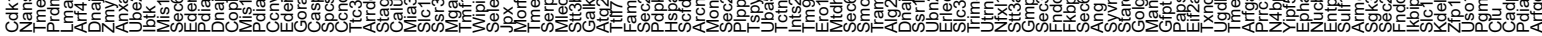

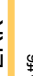

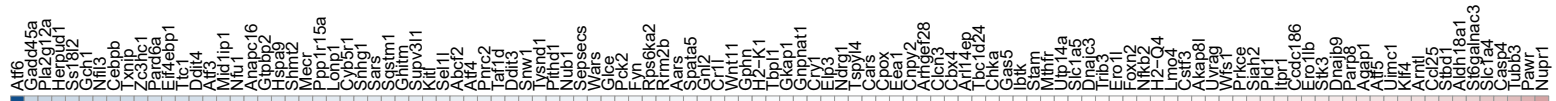

Figure 3 


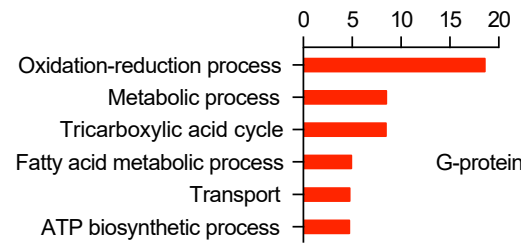

RNA-Seq TAC 2d

D

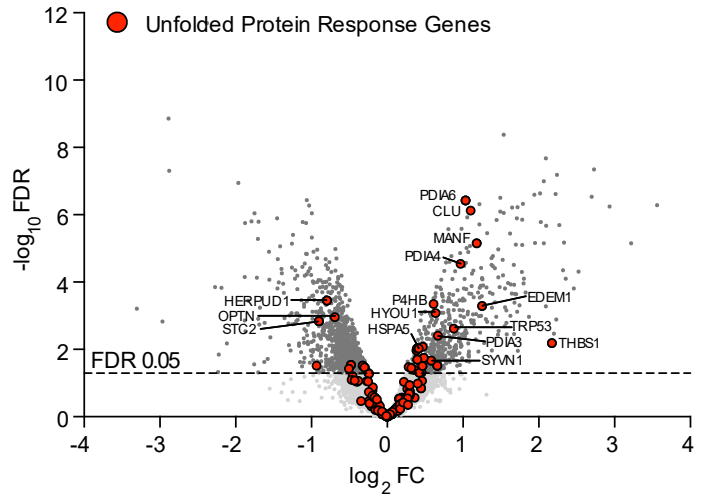

E

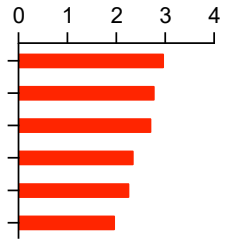

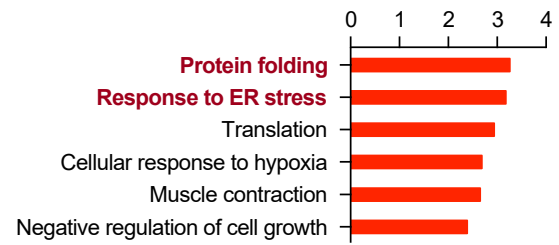

Ribosome Profiling TAC 2d
F

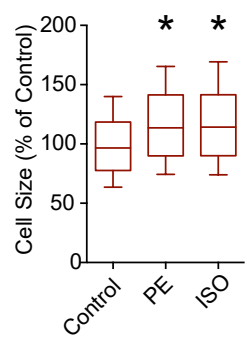

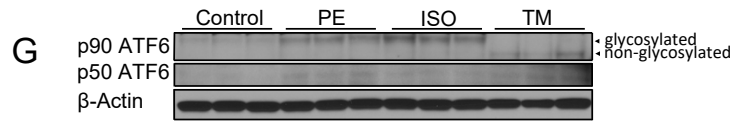

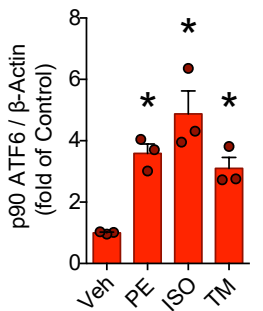

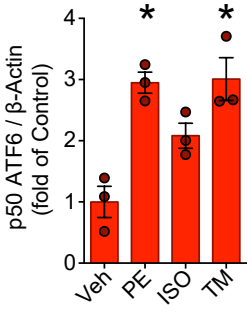

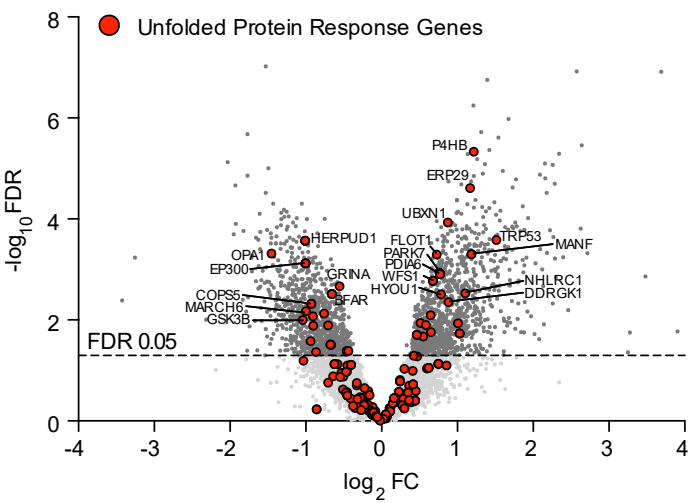

$\mathrm{H}$
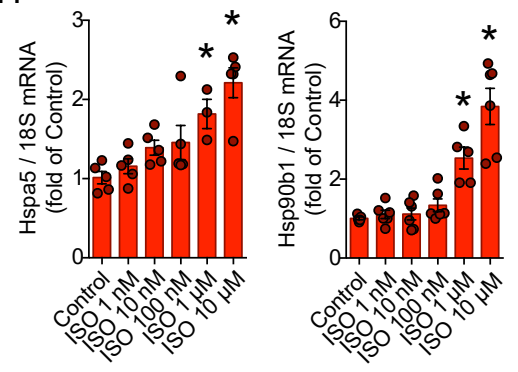

I
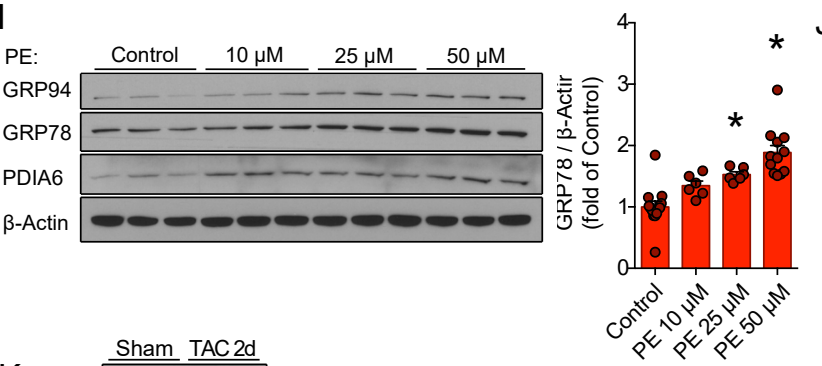

K

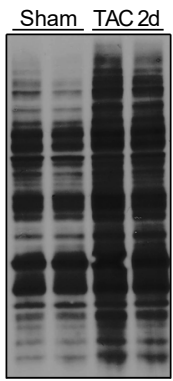

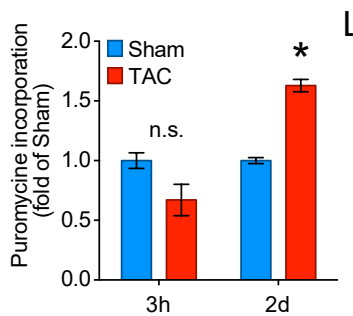

$\mathrm{L}$

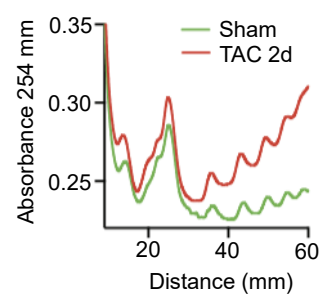

M

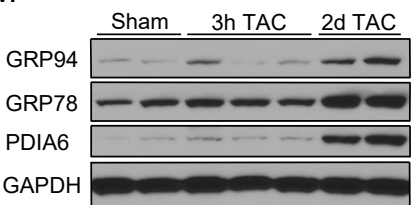

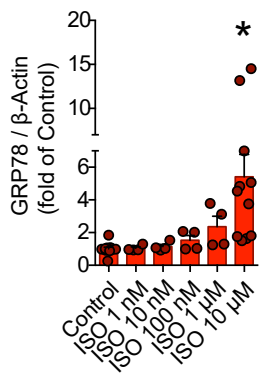

$\overline{\text { Mono- }} \overline{\text { Polysome }}$

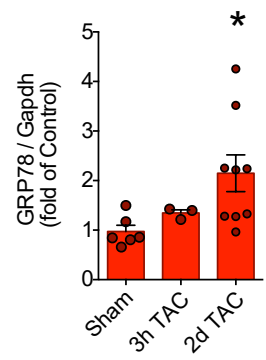



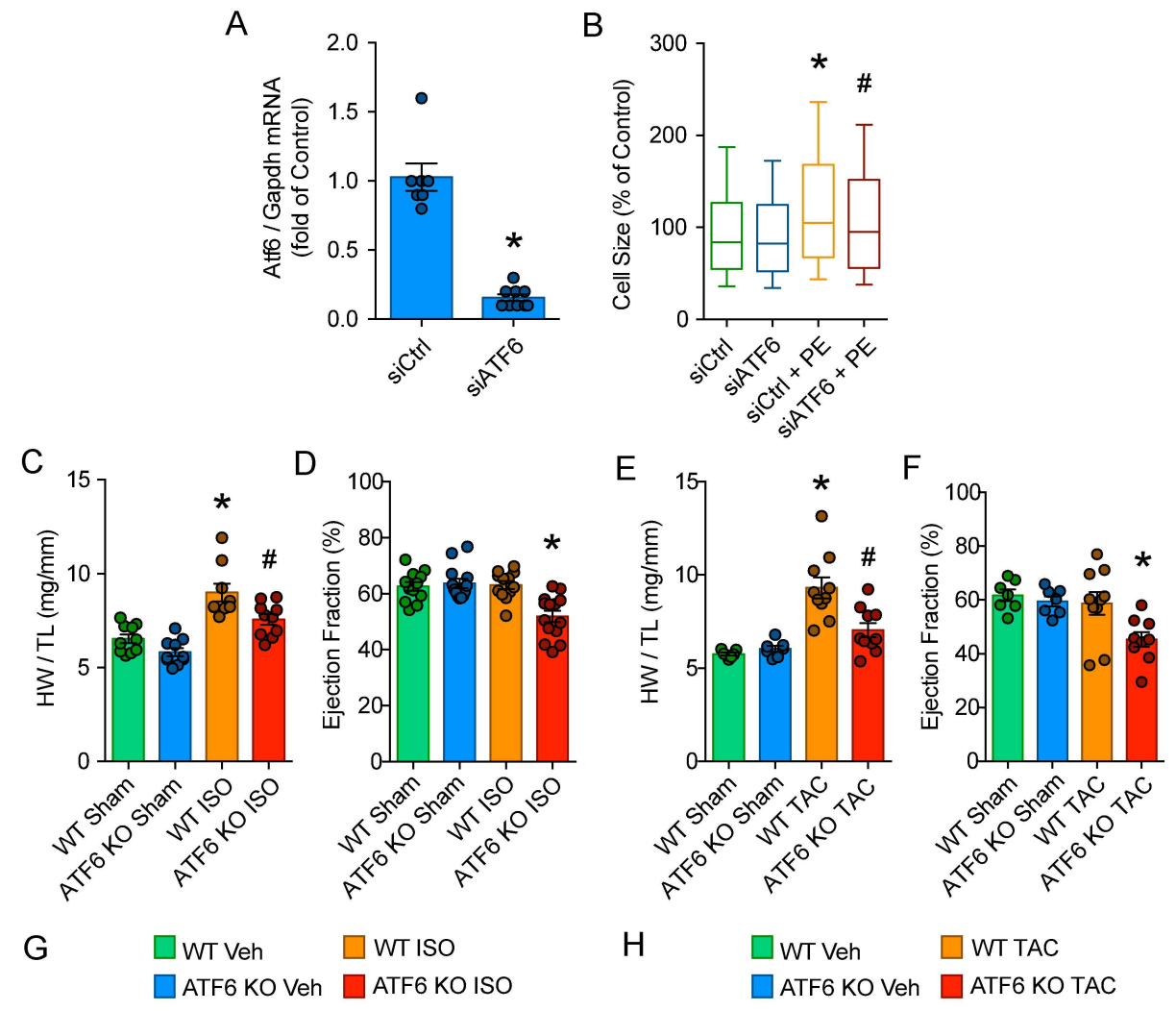

$\begin{array}{ll}\mathrm{H} \square \text { WT Veh } & \square \text { WT TAC } \\ & \square \text { ATF6 KO Veh } \square \text { ATF6 KO TAC }\end{array}$
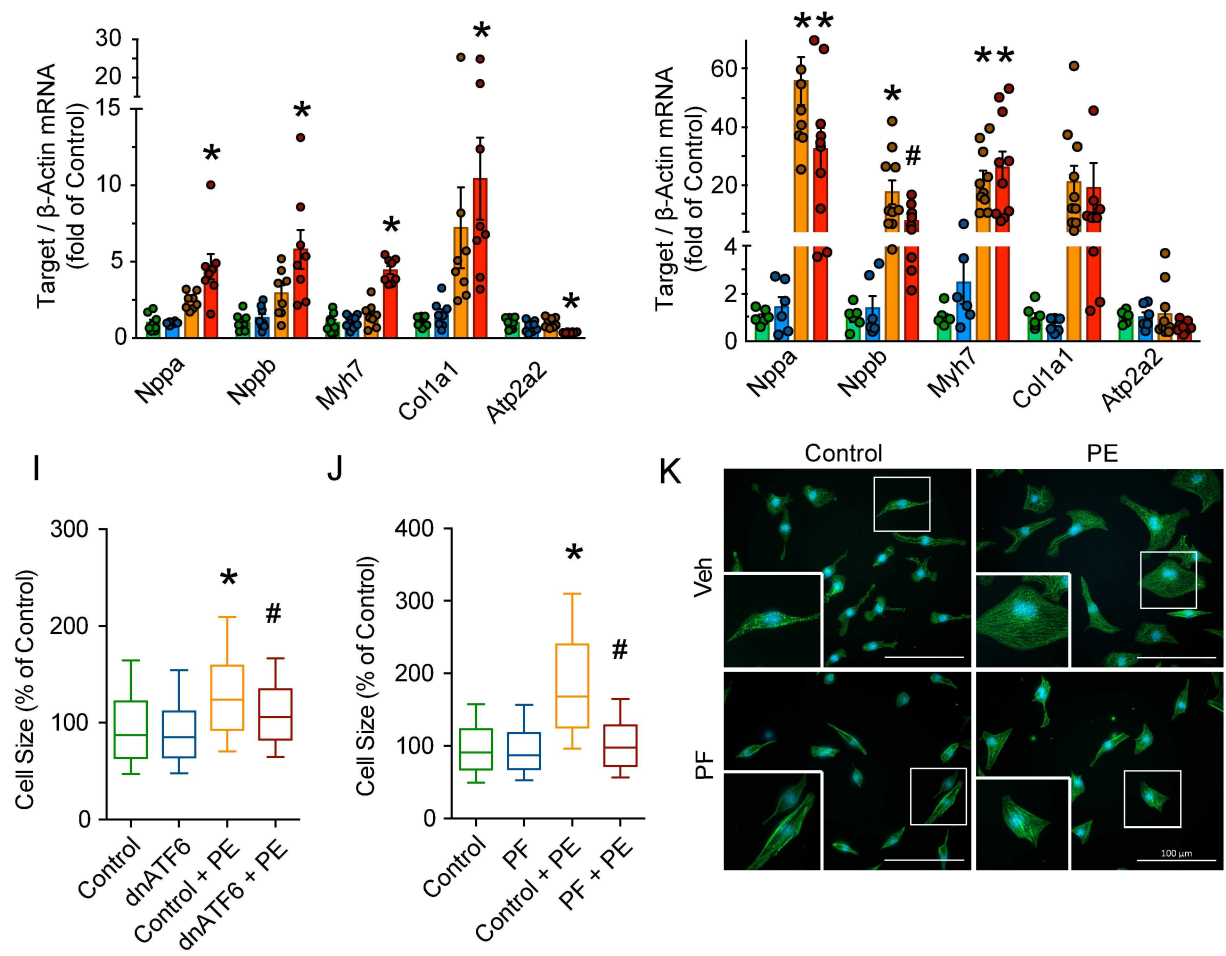

Figure 5 
A

\begin{tabular}{|c|c|c|c|}
\hline & Sham & \multicolumn{2}{|c|}{ TAC } \\
\hline & ATF6 KO & WT & ATF6 KO \\
\hline p90 ATF6 & -- & -- & - \\
\hline 50 ATF6 & & --1 & \\
\hline Actin & & & \\
\hline
\end{tabular}

B $\square$ WT Sham $\square$ WT ISO
$\square$ ATF6 KO Sham $\square$ ATF6 KO ISO

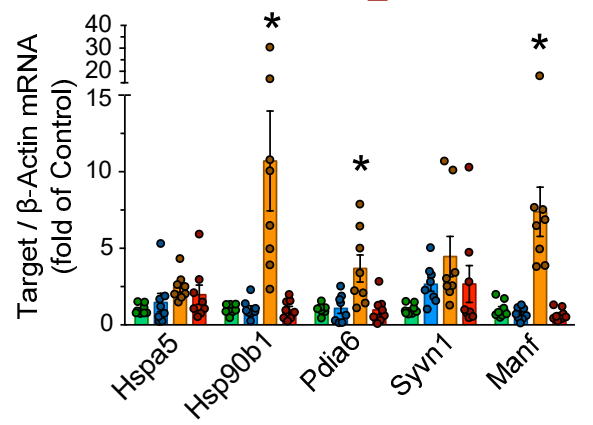

C $\square$ WT Sham $\square$ WT TAC

$\square$ ATF6 KO Sham $\square$ ATF6 KO TAC

D
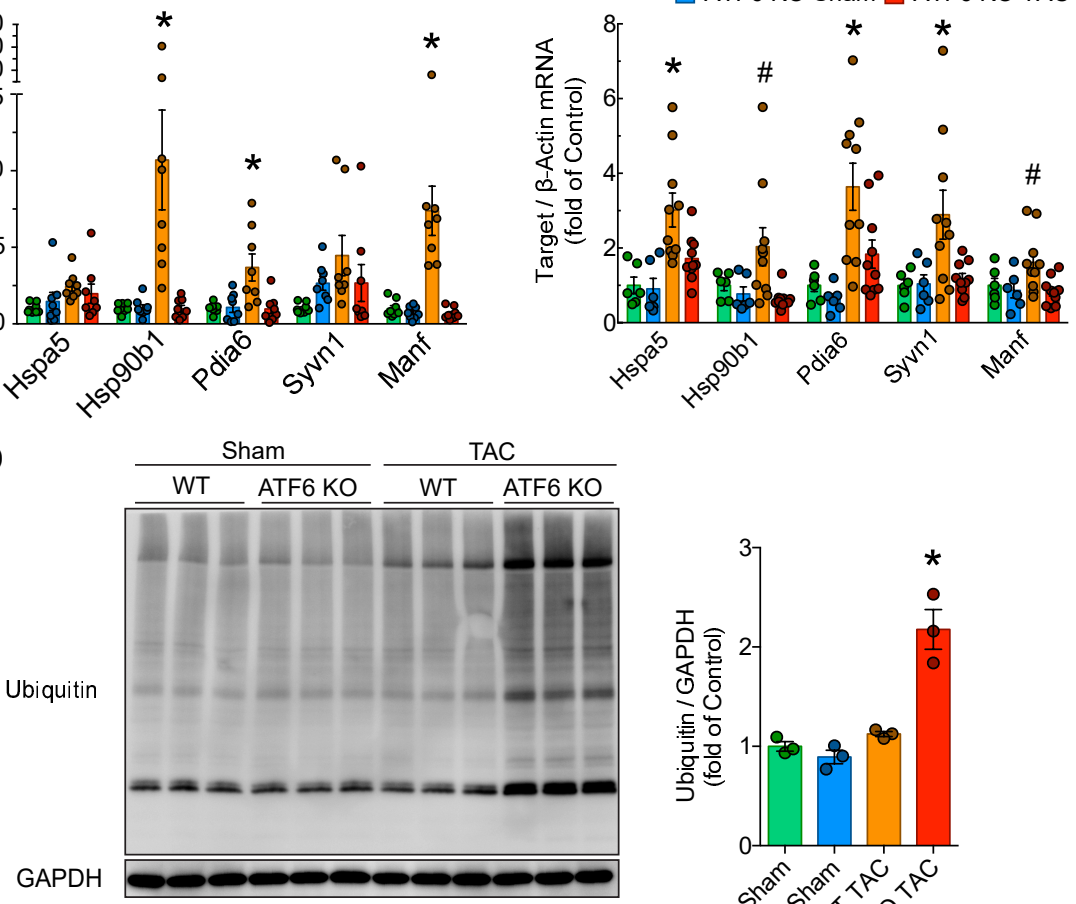

E

Sham
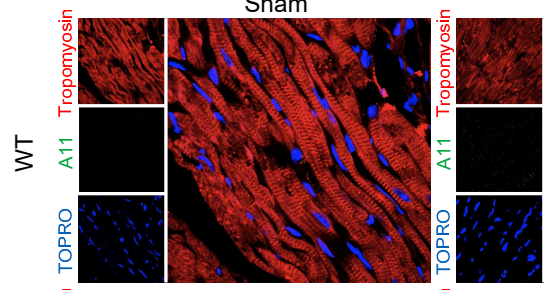

TAC
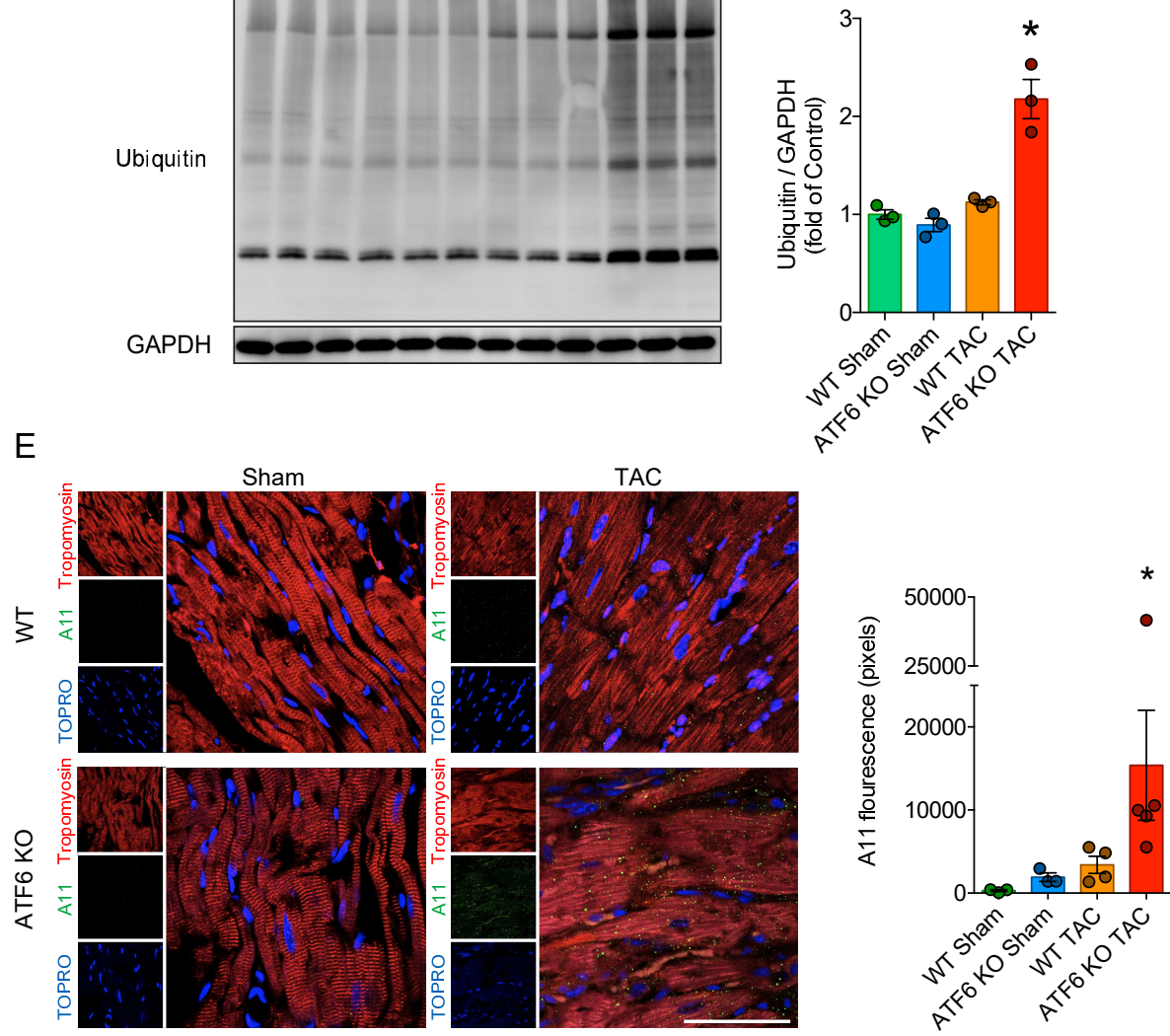

Figure 6 